\title{
Manejo do lodo de esgoto e nitrogênio mineral na fertilidade do solo ao longo do tempo
}

\section{Management of sewage sludge and mineral nitrogen in soil fertility over time}

\author{
Thomaz Figueiredo Lobo ${ }^{1 *}$; Helio Grassi Filho²; Leonardo Theodoro Bull²; Lais \\ Lorena Queiroz Moreira ${ }^{3}$
}

\section{Resumo}

A utilização de lodo de esgoto é uma prática promissora para o desenvolvimento de sistemas agrícolas sustentáveis. O objetivo deste trabalho foi verificar a melhoria na fertilidade do solo sobre diferentes manejos de lodo de esgoto e de nitrogênio mineral após 7 aplicações deste resíduo. O experimento foi conduzido na Fazenda Experimental São Manuel pertencente à Faculdade de Ciências Agronômicas da UNESP de Botucatu, localizada no município de São Manuel. Foi adotado um delineamento experimental em blocos casualizados constituído por 6 tratamentos e 5 repetições assim definidos: T0 sem adubação nitrogenada, T1 - adubação química nitrogenada de acordo com a necessidade da cultura, T2 - 50\% adubação nitrogenada proveniente do lodo de esgoto e 50\% na forma da adubação química, T3 - 100\% da adubação nitrogenada do recomendado pela cultura, proveniente do lodo de esgoto, T4 - $150 \%$ da adubação nitrogenada proveniente do lodo de esgoto e T5 - 200\% da adubação nitrogenada proveniente do lodo de esgoto. Foram feitas sete aplicações de lodo de esgoto com as seguintes culturas (ano 1 - girassol, ano 2 girassol, ano 3 - aveia e feijão, ano 4 - triticale e girassol, ano 5 - trigo), sendo que as três primeiras aplicações foram com lodo de esgoto tratado e as demais aplicações foram com lodo compostado. Na profundidade de 0 a $20 \mathrm{~cm}$ o lodo de esgoto promoveu um incremento nos teores de matéria orgânica, $\mathrm{P}, \mathrm{S}, \mathrm{H}+\mathrm{Al}, \mathrm{CTC}$ e decréscimo no $\mathrm{pH}$ do solo. Na profundidade de $20 \mathrm{a} 40 \mathrm{~cm}$ o lodo de esgoto promoveu uma diminuição no $\mathrm{pH}$ e aumento nos teores de matéria orgânica, $\mathrm{P}, \mathrm{H}+\mathrm{Al}, \mathrm{K}$, $\mathrm{Ca}, \mathrm{SB}, \mathrm{CTC}$ e S. O N mineral influenciou o aumento do S na profundidade de $20 \mathrm{a} 40 \mathrm{~cm}$.

Palavras-chave: Sustentabilidade, matéria orgânica e acidez do solo

\begin{abstract}
The use of sewage sludge is a practice highly promising for the development of sustainable agricultural systems. The objective of this study was to assess the improvement in soil fertility management strategies on different sewage sludge and mineral nitrogen after seven application of this residue. The experiment was carried at the São Manuel Experimental Farm belonging to the faculty of Agronomic Sciences of UNESP, Botucatu, located in the county of São Manuel. It was adopted the experimental design in a randomized blocks consisting of six treatments and five repetitions defined as follows: T0 - without
\end{abstract}

\footnotetext{
${ }^{1}$ Eng $^{\circ}$ Agro , Pós-Doutorando do Curso de Irrigação, Universidade Estadual Paulista “Julio de Mesquita Filho", UNESP, Botucatu, SP. E-mail: thomaz.lobo@superig.com.br

${ }^{2}$ Eng $^{\text {ss }}$ Agr $^{\text {'s }}$, Drs. do Dept ${ }^{\circ}$ de Recursos Naturais e Ciência do Solo, UNESP, Botucatu, SP. E-mail: heliograssi@fca.unesp.br; bull@fca.unesp.br

${ }^{3}$ Eng $^{\mathrm{a}}$ Agr $^{\mathrm{a}}$, Discente de Mestrado do curso de irrigação, UNESP, Botucatu, SP. E-mail: moreira.laislorena@yahoo.com.br

* Autor para correspondência
} 
nitrogen fertilizer, $\mathrm{T} 1$ - mineral fertilizer nitrogen according to the crop needs, $\mathrm{T} 2-50 \%$ nitrogen from sewage sludge and 50\% in the form of chemical fertilizer, T3 - 100\% of nitrogen recommended by the culture, from sewage sludge, T4 - $150 \%$ of nitrogen recommended by the culture, from sewage sludge and T5 $-200 \%$ of the nitrogen from the sewage sludge. It has done seven application of sewage sludge in crop (year 1 - sunflower, year 2 sunflower, year 3 - oats and bean, year 4 - triticale and sunflower, year 5 - wheat) and the first three applications were treated with sewage sludge and the other applications were composted sludge. In the depth $0-20 \mathrm{~cm}$, the sewage sludge promoted an increase in levels of organic matter, $\mathrm{P}, \mathrm{S}, \mathrm{H}+\mathrm{Al}, \mathrm{CEC}$ and decreased in soil $\mathrm{pH}$. In the depth of 20 to $40 \mathrm{~cm}$ the sewage sludge promoted a decrease in $\mathrm{pH}$ and increase in soil organic matter, $\mathrm{P}, \mathrm{H}+\mathrm{Al}, \mathrm{K}, \mathrm{Ca}, \mathrm{SB}, \mathrm{CEC}$ and $\mathrm{S}$. Mineral N influence the increase in the depth $\mathrm{S}$ of $20-40 \mathrm{~cm}$.

Key words: Sustainability, organic matter and soil acidity

\section{Introdução}

A população está crescendo de uma forma muito rápida e a produção de resíduos acompanha este crescimento, aumentando cada vez mais a produção de lodo de esgoto e águas residuárias nas ETEs (Estações de Tratamentos de Esgotos). Estes resíduos, de uma forma geral, são depositados em aterros sanitários e lançados nos mananciais, sendo pouco aproveitados, tendo em vista que estes resíduos são ricos em nutrientes para as plantas e que de uma maneira ou outra poderiam ser utilizados na agricultura.

A disposição final do lodo de esgoto vem se caracterizando como um dos problemas ambientais urbanos mais relevantes da atualidade, e que cresce diariamente tanto nos países desenvolvidos quanto naqueles em desenvolvimento, com reflexos da ampliação das redes de coleta e incremento dos níveis de tratamento (PEGORINI et al., 2003).

A utilização de lodo de esgoto é uma prática altamente promissora para o desenvolvimento de sistemas agrícolas sustentáveis. No entanto, normas rígidas pela elaboração de projetos devem ser seguidas para minimizar o impacto desta prática no ambiente, a norma técnica P4.240 (CONAMA, 2006).

Os lodos de esgotos são, de uma maneira geral, fertilizantes nitrogenados. Além do N, o lodo de esgoto contém $\mathrm{P}$ e micronutrientes essenciais, como $\mathrm{Fe}, \mathrm{Cu}, \mathrm{Mn}$ e Zn. Normalmente a concentração de K no lodo de esgoto é baixa para suprir as necessidades das culturas agrícolas. Quando aplicado em taxas agronômicas, os lodos de esgotos podem reduzir em muito o custo de produção, pela menor utilização de fertilizantes minerais solúveis. No Colorado (EUA), a constante aplicação de 7,5 ton ha-1 de lodo de esgoto a cada dois anos resulta uma produção de trigo comparável com uma aplicação de $55-65 \mathrm{~kg} \mathrm{~N}$ $\mathrm{ha}^{-1}$, na forma de fertilizante nitrogenado comercial. Na região metropolitana de São Paulo, estima-se uma produção de aproximadamente $500 \mathrm{t}$ de lodo de esgoto seco por dia. Considerando-se uma média de $3 \%$ de $\mathrm{N}$ orgânico e uma taxa de mineralização de $20 \%$ ao ano, somente os lodos de esgotos da região metropolitana de São Paulo poderiam suprir 3 ton de N por dia (LAMBAIS; SOUZA, 2000).

Trannin, Silveira e Moreira (2008) verificou que com o aumento da dose de lodo de esgoto aumentou a matéria orgânica do solo principalmente após a segunda aplicação. Rivero et al. (2004), em estudos que objetivou avaliar o impacto do composto na qualidade de solo tropical, aplicaram, durante três anos, doses de $0,37,74,148$ e $444 \mathrm{t} \mathrm{ha}^{-1}$ de composto a base seca, verificando, após este período, que a adição de composto aumentou a quantidade e a qualidade da matéria orgânica devido ao incremento de ácidos húmicos, o que resultou em melhoria na fertilidade do solo. Em solos tropicais, os efeitos da adição de lodo de esgoto sobre o carbono orgânico, quando ocorrem, são temporários (VAZ; GONÇALVES, 2002; CARMO, 2001), porem, alguns estudos tem verificado, em longo prazo, aumentos lineares nos teores de carbono no solo com 
aumento de doses de lodo de esgoto (OLIVEIRA et al., 2002; MARQUES, 1996). Dias (2005) concluiu em um de seus trabalhos que o teor e o estoque de carbono aumentaram significativamente na camada superficial do solo $(0-20 \mathrm{~cm})$ com acréscimo de dose de lodo de esgoto aplicado.

O lodo de esgoto é um resíduo que poderá ser reaproveitado para a agricultura desde que seja bem manejado, ou seja, fazer recomendações pela necessidade de $\mathrm{N}$ para evitar a lixiviação excessiva de nitrato, utilizar lodo que tenha teores de metais pesados adequado seguindo a legislação estabelecida pelo CONAMA, (2006).

O objetivo deste trabalho foi verificar o efeito na fertilidade do solo sobre diferentes manejos de lodo de esgoto e nitrogênio mineral após 7 aplicações deste resíduo.

\section{Material e Métodos}

O experimento foi conduzido na Fazenda Experimental São Manuel pertencente à Faculdade de Ciências Agronômicas da UNESP de Botucatu, localizada no município de São Manuel a $\left(22^{\circ} 25^{\text {, }}\right.$ S; Latitude Sul, $\left.48^{\circ} 34^{\prime} \mathrm{W}\right)$ Longitude Oeste de Greenwich, com altitude de 750 m. s.n.m.. O clima da região, segundo a classificação de Köppen, é do tipo mesotérmico, Cwa, ou seja, subtropical úmido com estiagem no período de inverno, e com chuvas de novembro a abril sendo a precipitação média anual do município de $1.433 \mathrm{~mm}$. A umidade relativa do ar é de $71 \%$, com temperatura média de $23^{\circ} \mathrm{C}$, medias anual. A classificação e os dados meteorológicos foram fornecidos pelo Departamento de Recursos Naturais, área de Ciências Ambientais / FCA UNESP - Botucatu.

A classificação do solo onde foi instalado este experimento é Latossolo Vermelho Escuro (EMBRAPA, 1999).

Antecedendo a instalação do experimento, foram realizadas análises químicas de solo nas faixas de profundidades de $0-20$ a $20-40 \mathrm{~cm}$, segundo Raij et al. (2001), estando os resultados apresentados na Tabela 1.

Tabela 1. Características químicas iniciais do solo.

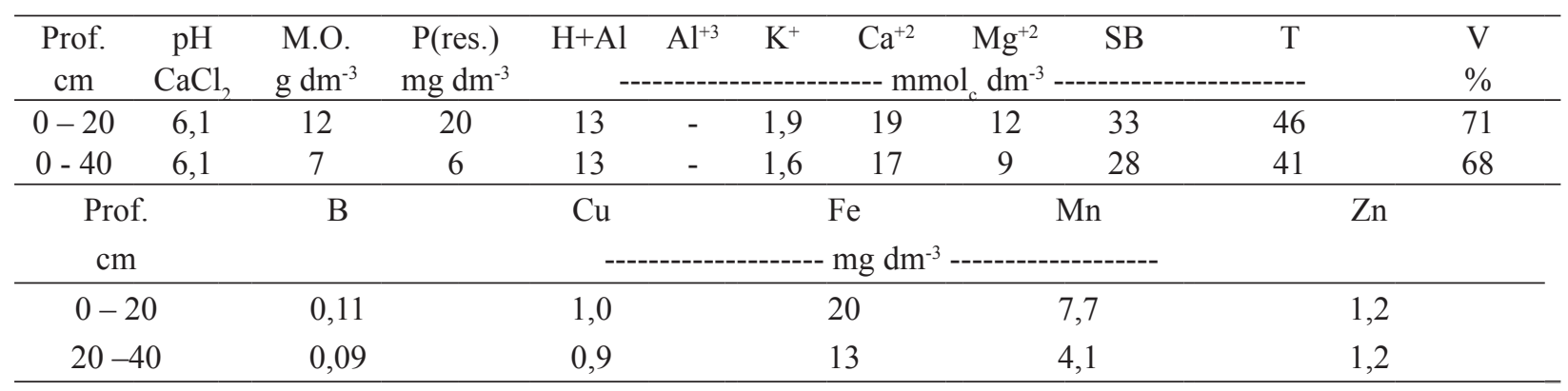

Fonte: Elaboração dos autores.

Foi adotado o delineamento experimental em e 5 repetições assim definidos Pimentel Gomes blocos casualizados constituído por 6 tratamentos (2000): 
- T0 sem adubação nitrogenada (testemunha);

- T1 adubação química nitrogenada de acordo com o Boletim Técnico 100 (RAIJ et al., 1997) (Adubação 100\% N químico);

- T2 $50 \%$ adubação nitrogenac
química, em cobertura;

- T3 100\% da adubação nitrogenada do recomendado pela cultura, proveniente do lodo de esgoto;

- T4 150\% da adubação nitrogenada proveniente do lodo de esgoto;

- T5 200\% da adubação nitrogenada proveniente do lodo de esgoto.

Cada parcela foi constituída por uma área de 100 metros quadrados $(14 \times 7,2 \mathrm{~m})$ com uma distância de $3 \mathrm{~m}$ de uma parcela a outra do mesmo bloco. A distância entre um bloco ao outro foi de $1,8 \mathrm{~m}$.

$\mathrm{O}$ cálculo do $\mathrm{N}$ proveniente do lodo de esgoto foi feito levado em consideração a sua taxa de mineralização do nitrogênio de $30 \%$ durante o ciclo da cultura segundo CONAMA (2006).
Utilizou-se o lodo de esgoto proveniente da Estação de Tratamento de Esgoto da cidade de Jundiaí/SP, cujas características são apresentadas na Tabela 2. As análises, a partir de amostras compostas, foram realizadas no Laboratório de Fertilizantes e Corretivos do Departamento de Recursos Naturais / Ciência do Solo da Faculdade de Ciências Agronômica de Botucatu - SP, seguindo metodologia de Coelho et al. (1998).

Tabela 2. Características químicas do lodo de esgoto utilizado no experimento.

\begin{tabular}{|c|c|c|c|c|c|c|c|c|c|c|c|c|c|c|c|c|}
\hline & $\mathrm{N}$ & $\mathrm{P}_{2} \mathrm{O}_{5}$ & $\mathrm{~K}_{2} \mathrm{O}$ & Umid. & MO & C & $\mathrm{Ca}$ & $\mathrm{Mg}$ & $\mathrm{S}$ & $\mathrm{Na}$ & $\mathrm{Cu}$ & $\mathrm{Fe}$ & $\mathrm{Mn}$ & $\mathrm{Zn}$ & $\mathrm{C} / \mathrm{N}$ & $\mathrm{pH}$ \\
\hline ano & & & & ------. & $---\%$ & - & 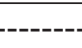 & ----- & & & 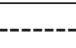 & $---\mathrm{mg} \mathrm{l}$ & $\mathrm{g}^{-1}---$ & & & \\
\hline $1^{\circ}$ & 3,2 & 1,7 & 0,18 & 67,6 & 55 & 30,6 & 1,25 & 0,22 & 4,6 & 1520 & 812 & 31650 & 3400 & 2150 & $10 / 1$ & 4,30 \\
\hline $2^{\circ}$ & 3,6 & 1,6 & 0,22 & 67,6 & 58 & 32,2 & 1,73 & 0,30 & 1,8 & 1760 & 650 & 11850 & 670 & 500 & $9 / 1$ & 6,00 \\
\hline $3^{\circ}$ & 3,9 & 2,1 & 0,16 & 57,0 & 58 & 32,3 & 1,10 & 0,19 & 4,7 & 1160 & 428 & 23450 & 630 & 3000 & $8 / 1$ & 6,05 \\
\hline $4^{\circ}$ & 2,4 & 2,0 & 0,40 & 50,0 & 55 & 31,0 & 1,90 & 0,30 & 1,6 & 1340 & 304 & 23250 & 472 & 3750 & $13 / 1$ & 6,60 \\
\hline $5^{\circ}$ & 2,3 & 2,0 & 0,40 & 60,0 & 50 & 28,4 & 1,90 & 0,30 & 1,6 & 1340 & 304 & 23250 & 472 & 3750 & $12 / 1$ & 6,60 \\
\hline $6^{\circ}$ & 2,4 & 2,0 & 0,40 & 58,0 & 53 & 29,4 & 1,90 & 0,30 & 1,6 & 1340 & 304 & 23250 & 472 & 3750 & $12 / 1$ & 6,60 \\
\hline $7^{\mathrm{o}}$ & 2,0 & 1,3 & 0,19 & 51,0 & 51 & 28,3 & 1,06 & 0,17 & 0,8 & 920 & 84 & 12050 & 270 & 550 & $14 / 1$ & 6,25 \\
\hline
\end{tabular}

Fonte: Elaboração dos autores.

As quantidades aplicadas de lodo para cada tratamento estão apresentadas na Tabela 3: 
Tabela 3. Quantidades de lodo de esgoto para cada tratamento.

\begin{tabular}{ccccccccc}
\hline & $1^{\mathrm{a}}$ & $2^{\mathrm{a}}$ & $3^{\mathrm{a}}$ & $\begin{array}{c}4^{\mathrm{a}} \\
\text { Tratamento }\end{array}$ & & \multicolumn{7}{c}{$5^{\mathrm{a}}$} & $6^{\mathrm{a}}$ & $7^{\mathrm{a}}$ & total \\
\hline T2 & 7.600 & 7.094 & 7.000 & 10.000 & 8.984 & 8.768 & 10.700 & 51.378 \\
T3 & 15.200 & 14.187 & 14.000 & 20.000 & 17.968 & 17.536 & 21.400 & 102.756 \\
T4 & 22.800 & 21.281 & 21.000 & 30.000 & 26.952 & 26.305 & 32.099 & 154.134 \\
T5 & 30.400 & 28.374 & 28.000 & 40.000 & 35.936 & 35.073 & 42.798 & 205.512 \\
\hline
\end{tabular}

Fonte: Elaboração dos autores.

Este composto de lodo de esgoto utilizado apresenta dentro das normas do CONAMA, (2006) quanto à patógenos e metais pesados.

Foram feitas sete aplicações de lodo de esgoto com as seguintes culturas (ano 1 - girassol, ano 2 girassol, ano 3 - aveia e feijão, ano 4 - triticale e girassol, ano 5 - trigo), sendo que as três primeiras aplicações foram com lodo de esgoto tratado e incorporado a $10 \mathrm{~cm}$ e as demais aplicações foram com lodo compostado em sistema de semeadura direta.

Na primeira cultura de girassol a adubação de semeadura para todas as parcelas foi constituída de $30 \mathrm{~kg} \mathrm{ha}^{-1}$ de $\mathrm{P}_{2} \mathrm{O}_{5}$ na forma de superfosfato simples (180 $\mathrm{g} \mathrm{kg}^{-1} \mathrm{P}_{2} \mathrm{O}_{5}$ ) e $30 \mathrm{~kg} \mathrm{ha}^{-1}$ de $\mathrm{K}_{2} \mathrm{O}$ na forma de cloreto de potássio (600 $\left.\mathrm{g} \mathrm{kg}^{-1} \mathrm{~K}_{2} \mathrm{O}\right)$. A adubação de $\mathrm{N}$ foi realizada logo após o plantio no $\mathrm{T} 1$, na dosagem de $10 \mathrm{~kg} \mathrm{ha}^{-1}$ de $\mathrm{N}$ na forma de uréia (450 $\mathrm{g} \mathrm{kg}^{-1}$ de N), que é o recomendado para o Estado de São Paulo. Os tratamentos T0, T2, T3, T4 e T5 não receberam esta adubação com $\mathrm{N}$; adubação de cobertura - os tratamentos que receberam a adubação de cobertura foram os tratamentos $\mathrm{T} 1 \mathrm{e}$ T2. O tratamento $\mathrm{T} 1$ recebeu $40 \mathrm{~kg} \mathrm{ha}^{-1}$ de $\mathrm{N}$, que é o recomendado paro o Estado de São Paulo, de acordo com o Boletim 100 (RAIJ et al., 1997), o tratamento $\mathrm{T} 2$ recebeu $25 \mathrm{~kg} \mathrm{ha}^{-1}$ de $\mathrm{N}$, porque os outros $25 \mathrm{~kg} \mathrm{ha}^{-1}$ foram aplicados antes do plantio na forma de lodo de esgoto, totalizando os $50 \mathrm{~kg}$ ha $^{-1}$ que é o recomendado para o Estado de São Paulo. A forma utilizada para a cobertura foi a uréia. Esta operação foi realizada aos 30 dias após a emergência, como choveu após esta adubação não houve necessidade de incorporar; adubação foliar foi feito uma aplicação foliar de B aos 45 dias após o plantio, na dosagem de $1 \mathrm{~g} \mathrm{~L}^{-1}$ de ácido bórico.

No segundo ano de girassol a adubação de semeadura para todas as parcelas foi constituída de $30 \mathrm{~kg} \mathrm{ha}^{-1}$ de $\mathrm{P}_{2} \mathrm{O}_{5}$ na forma de superfosfato simples (180 $\mathrm{g} \mathrm{kg}^{-1} \mathrm{P}_{2} \mathrm{O}_{5}$ ) e $30 \mathrm{~kg} \mathrm{ha}^{-1}$ de $\mathrm{K}_{2} \mathrm{O}$ na forma de cloreto de potássio $\left(600 \mathrm{~g} \mathrm{~kg}^{-1} \mathrm{~K}_{2} \mathrm{O}\right)$. A adubação de $\mathrm{N}$ foi realizada logo após o plantio no T1, na dosagem de $10 \mathrm{~kg} \mathrm{ha}^{-1}$ de $\mathrm{N}$ na forma de uréia (450 $\mathrm{g} \mathrm{kg}^{-1}$ de N), que é o recomendado para o Estado de São Paulo. A adubação de cobertura foi executada nos tratamentos T1 e T2. O tratamento T1 recebeu $40 \mathrm{~kg} \mathrm{ha}^{-1}$ de $\mathrm{N}$, que é o recomendado paro o Estado de São Paulo, de acordo com o Boletim 100 (RAIJ et al., 1997), o tratamento T2 recebeu $25 \mathrm{~kg} \mathrm{ha}^{-1}$ de N. A forma utilizada para a cobertura foi à uréia.

$\mathrm{Na}$ semeadura de aveia não foi realizada adubação de semeadura, foi realizado adubação mineral com $\mathrm{N}$ somente nos tratamentos T1 e T2 nas doses de 35 e $70 \mathrm{~kg} \mathrm{ha}^{-1}$ utilizou como fonte a uréia e foi feito na fase de perfilhamento.

No feijoeiro foi executada uma calagem nas parcelas em que houve necessidade, utilizando uma dosagem de 1,4 ton ha ${ }^{-1}$ de calcário dolomítico com PRNT de $90 \%$ e teor de $\mathrm{CaO}$ de $32 \%$ e $\mathrm{MgO}$ de $13 \%$. Essa dosagem foi baseada nas análises de solo retiradas no final da cultura da aveia. O cálculo dessa dosagem foi fundamentado na parcela que apresentou uma $\mathrm{V} \%$ menor, que foi a parcela que aplicou uma maior dose de lodo de esgoto, conforme a Tabela 4. Nas parcelas que apresentaram uma V\% superior a $70 \%$ não foram realizadas a calagem. 
A adubação de semeadura foi efetuada com base na média da análise de solo da cultura anterior, utilizando como fonte de $\mathrm{N}$ a uréia de $\mathrm{P}$ superfosfato triplo e $\mathrm{K}$ cloreto de potássio. Foi realizada uma adubação nitrogenada de cobertura, aos 29 dias após a semeadura, nos tratamentos T1 e T2 nas dosagens de 60 e $35 \mathrm{~kg} \mathrm{ha}^{-1}$ de $\mathrm{N}$, respectivamente. A fonte utilizada foi a uréia.

Tabela 4. Características químicas do solo da parcela de menor V\% (básicas).

\begin{tabular}{|c|c|c|c|c|c|c|c|c|c|c|c|}
\hline \multirow{2}{*}{$\begin{array}{l}\text { Prof. } \\
\mathrm{cm}\end{array}$} & \multirow{2}{*}{$\begin{array}{c}\mathrm{pH} \\
\mathrm{CaCl}_{2}\end{array}$} & \multirow{2}{*}{$\begin{array}{l}\text { M.O. } \\
\mathrm{g} \mathrm{dm}^{-3}\end{array}$} & \multirow{2}{*}{$\begin{array}{l}\mathrm{P}(\text { res. }) \\
\mathrm{mg} \mathrm{dm}^{-3}\end{array}$} & $\mathrm{H}+\mathrm{Al}$ & $\mathrm{Al}^{+3}$ & $\mathrm{~K}^{+}$ & $\mathrm{Ca}^{+2}$ & $\mathrm{Mg}^{+2}$ & SB & $\mathrm{T}$ & V \\
\hline & & & & & --- & $---m$ & $\mathrm{dm}^{-3}$ & & - & $\%$ \\
\hline $0-20$ & 4,7 & 30 & 23 & 28 & - & 2,2 & 17 & 5 & 24 & 53 & 46 \\
\hline
\end{tabular}

Fonte: Elaboração dos autores.

No triticale a adubação de semeadura foi elaborada uma mistura com superfosfato triplo $\left(46 \% \mathrm{P}_{2} \mathrm{O}_{5}\right)$ e cloreto de potássio $\left(60 \%\right.$ de $\left.\mathrm{K}_{2} \mathrm{O}\right)$. Essa composição foi de $80 \%$ de superfosfato triplo e $20 \%$ de cloreto de potássio, baseada na média dos teores de P e K das análises de solo efetuadas após a colheita da aveia (RAIJ et al., 1997). A dosagem dessa mistura foi de $178 \mathrm{~kg} \mathrm{ha}^{-1}$, que corresponde a $65 \mathrm{~kg} \mathrm{ha}^{-1}$ de $\mathrm{P}_{2} \mathrm{O}_{5}$ e $21 \mathrm{~kg} \mathrm{ha}^{-1}$ de $\mathrm{K}_{2} \mathrm{O}$, sendo que o recomendado pelo Boletim Técnico 100 é de 60 e $20 \mathrm{~kg} \mathrm{ha}^{-1}$ de $\mathrm{P}_{2} \mathrm{O}_{5}$ e $\mathrm{K}_{2} \mathrm{O}$, respectivamente. Após 27 dias da semeadura, foi efetuada a adubação nitrogenada no tratamento (T1), na dosagem de 25 $\mathrm{kg} \mathrm{ha}^{-1}$ de N. A fonte utilizada foi à uréia. Aos 40 dias de semeadura, efetuou-se a adubação com N nos tratamentos (T1, T2), na dosagem de $25 \mathrm{~kg} \mathrm{ha}^{-1}$ de $\mathrm{N}$, utilizando a uréia.

No girassol foi aplicado o Gliphosathe (ia), na dosagem de $2 \mathrm{~L} \mathrm{ha}^{-1}$, juntamente com o ácido bórico $(17 \% \mathrm{~B})$, na dosagem de $6 \mathrm{~kg} \mathrm{ha}^{-1}$, em um volume de calda de $320 \mathrm{~L} \mathrm{ha}^{-1}$, objetivando o controle de plantas daninhas e fornecimento de B para a cultura, elemento imprescindível para o girassol. Segundo Brighenti, Castro e Oliveira (2005) a adição de ácido bórico à calda de pulverização é uma maneira eficiente de fornecer B para a cultura do girassol. A quantidade de B utilizada foi de $1 \mathrm{~kg} \mathrm{ha}^{-1}$ do elemento, que é a recomendação para a cultura do girassol, segundo Raij et al. (1997). A adubação de plantio para todas as parcelas foi constituída de 51 $\mathrm{kg} \mathrm{ha}^{-1}$ de $\mathrm{P}_{2} \mathrm{O}_{5}$, na forma de superfosfato simples (170 $\mathrm{g} \mathrm{kg}^{-1} \mathrm{P}_{2} \mathrm{O}_{5}$ ), e $30,5 \mathrm{~kg} \mathrm{ha}^{-1}$ de $\mathrm{K}_{2} \mathrm{O}$, na forma de cloreto de potássio $\left(600 \mathrm{~g} \mathrm{~kg}^{-1} \mathrm{~K}_{2} \mathrm{O}\right)$. A adubação de $\mathrm{N}$ foi realizada 12 dias após o plantio no T1, na dosagem de $10 \mathrm{~kg} \mathrm{ha}^{-1}$ de $\mathrm{N}$, na forma de uréia (450 $\mathrm{g} \mathrm{kg}^{-1}$ de N). Os tratamentos T0, T2, T3, T4 e T5 não receberam essa adubação com $\mathrm{N}$, nessa ocasião. Os tratamentos que receberam a adubação de cobertura com $\mathrm{N}$ foram os tratamentos $\mathrm{T} 1$ e T2. O tratamento $\mathrm{T} 1$ recebeu $40 \mathrm{~kg} \mathrm{ha}^{-1}$ de $\mathrm{N}$; o tratamento $\mathrm{T} 2$ recebeu $25 \mathrm{~kg} \mathrm{ha}^{-1}$ de N. A fonte utilizada para a cobertura foi a uréia. Essa operação foi executada aos 30 dias após a emergência.

No trigo a adubação de semeadura foi efetuada uma mistura da fórmula $\left(01 \% \mathrm{~N}-16 \% \mathrm{P}_{2} \mathrm{O}_{5}-3,5 \%\right.$ $\left.\mathrm{K}_{2} \mathrm{O}\right)$ e cloreto de potássio $\left(60 \%\right.$ de $\left.\mathrm{K}_{2} \mathrm{O}\right)$. Dessa mistura, $70 \%$ foram da fórmula e $30 \%$ do cloreto de potássio. A dosagem dessa mistura foi de $110 \mathrm{~kg}$ $\mathrm{ha}^{-1}$, o que corresponde a $0,77 \mathrm{~kg} \mathrm{ha}^{-1}$ de $\mathrm{N}, 12,36$ kg. ha- ${ }^{-1}$ de $\mathrm{P}_{2} \mathrm{O}_{5}$ e $21,72 \mathrm{~kg} \mathrm{ha}^{-1}$ de $\mathrm{K}_{2} \mathrm{O}$. Aos 5 dias de semeadura foi realizado a adubação com N $35 \mathrm{~kg}$ $\mathrm{ha}^{-1}$ no tratamento $\mathrm{T} 1$ e aos 35 dias foi aplicado a mesma dose no tratamento $\mathrm{T} 1$ e $\mathrm{T} 2$ a fonte utilizada foi a uréia.

As amostras de solo foram retiradas no término dos ensaios nas profundidades de $0-20 \mathrm{~cm}$ e $20-40$ $\mathrm{cm}$. Foram retiradas $10 \mathrm{sub}$ amostras para formar uma amostra composta em cada parcela. As análises executadas foram: $\mathrm{pH}, \mathrm{MO}, \mathrm{P}, \mathrm{Ca}, \mathrm{Mg}, \mathrm{K}, \mathrm{H}+\mathrm{Al}, \mathrm{S}$, B, Cu, Fe, Mn e Zn (RAIJ et al., 2001). 
Os resultados foram submetidos à análise de variância e as médias comparadas pelo teste de Duncan 5\%. Nos tratamentos T0, T3, T4 e T5, que sofreram o aumento da dose de lodo efetuaramse uma regressão, para os parâmetros que houve diferença significativa no teste de média.

\section{Resultados e Discussões}

No $\mathrm{pH}$ do solo observa-se na Tabela 5 que onde não foi aplicado $\mathrm{N}$ mineral (T0) apresentou-se superior aos dois tratamentos que receberam uma maior dosagem de lodo de esgoto. Na Figura 1 A observa-se que com o aumento da dose de lodo ocorreu um decréscimo linear no $\mathrm{pH}$ do solo, isto pode ser explicado que ocorrendo o processo de nitrificação do $\mathrm{N}$, passando este de $\mathrm{NH}_{4}^{+}$para $\mathrm{NO}_{2}^{-}$ e posteriormente para $\mathrm{NO}_{3}^{-}$, através das bactérias nitrossomonas e nitrobacter respectivamente, foi liberado H para a solução do solo, com o aumento da dosagem de lodo que é rico em $\mathrm{N}\left(\mathrm{NH}_{4}^{+}\right)$então foi liberado mais $\mathrm{H}$ com o aumento da dose de lodo. A produção de ácidos orgânicos durante o processo de biodegradação da fração orgânica (CAMARGO et al., 1999) e a nitrificação (BOEIRA; LIGO; DYNIA, 2002) pode contribuir para a acidificação de solos tratados com lodo de esgoto. Comparando estes dados com a analise de solo inicial (Tabela 1) verifica-se que somente o tratamento $\mathrm{T} 0$ permaneceu no mesmo $\mathrm{pH}$. Segundo Raij et al. (2001) a media do T0 é considerado um valor muito alto do $\mathrm{pH}$, o T1, T2 e T3 são considerados valores altos e os tratamentos $\mathrm{T} 4$ e $\mathrm{T} 5$ apresentaram teores médios. Observa-se na Tabela 6 que o $\mathrm{pH}$ do solo na profundidade de 20 a $40 \mathrm{~cm}$ os tratamentos que receberam a maior dose de lodo (T4 e T5) foram inferiores que o tratamento que não recebeu $\mathrm{N}$ (T0) e do tratamento que recebeu $100 \% \mathrm{~N}$ do lodo de esgoto (T3). À medida que se aumentou a dose de lodo houve um decréscimo quadrático como mostra a Figura 2 A.

Figura 1. Analise básica do solo de 0 a $20 \mathrm{~cm}$ em função da dose de lodo compostado.
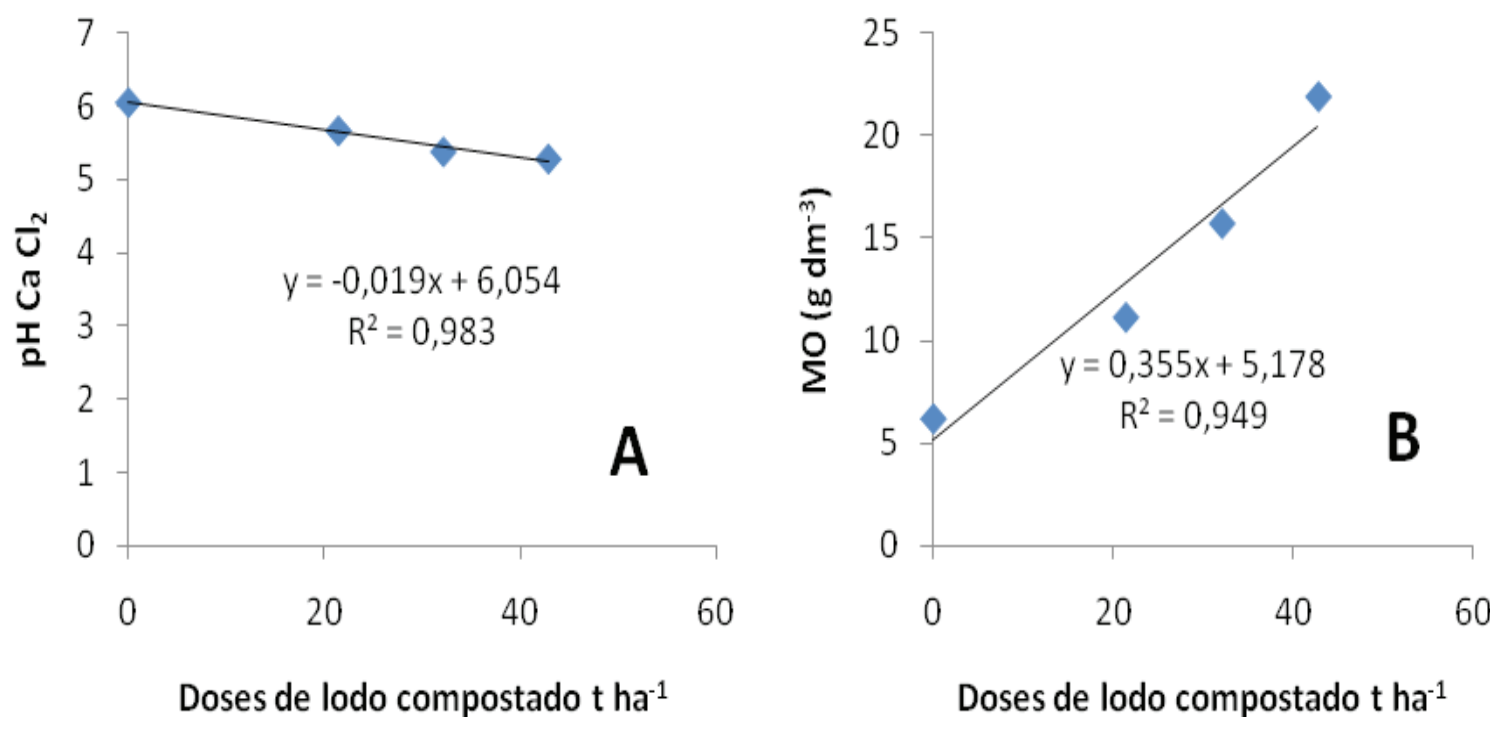

Doses de lodo compostado tha-1 

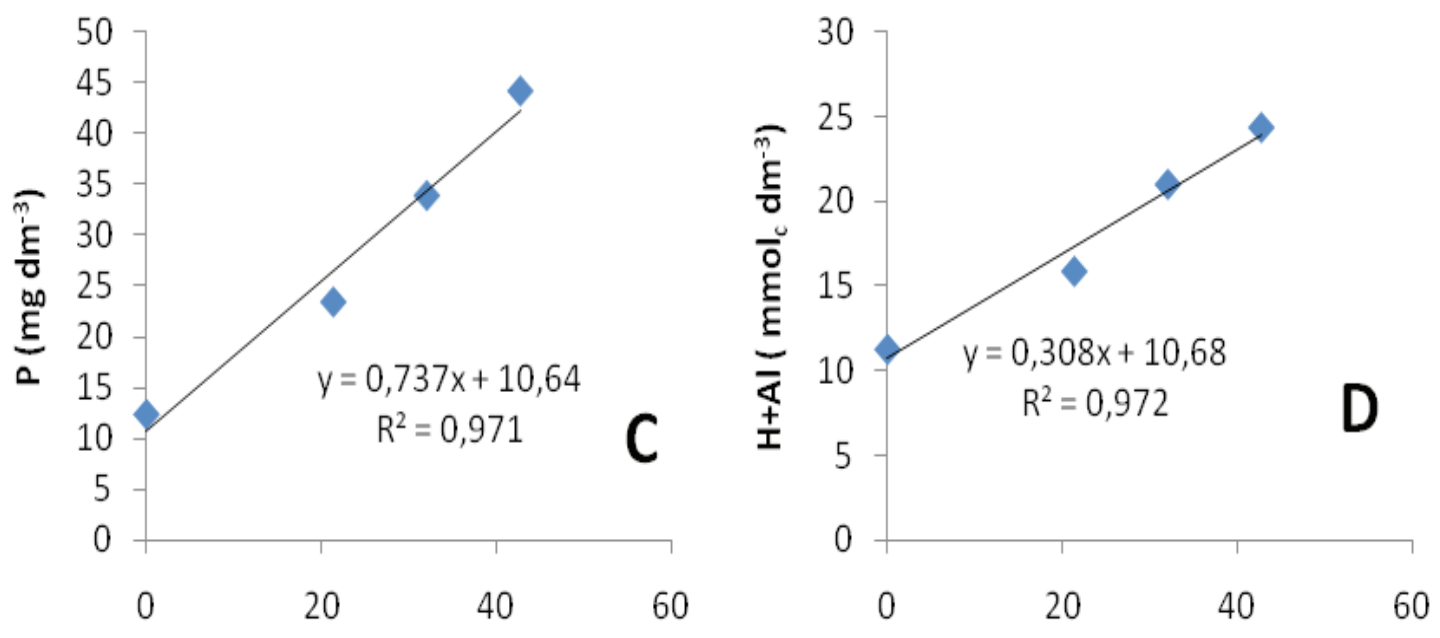

Doses de lodo compostado tha-1
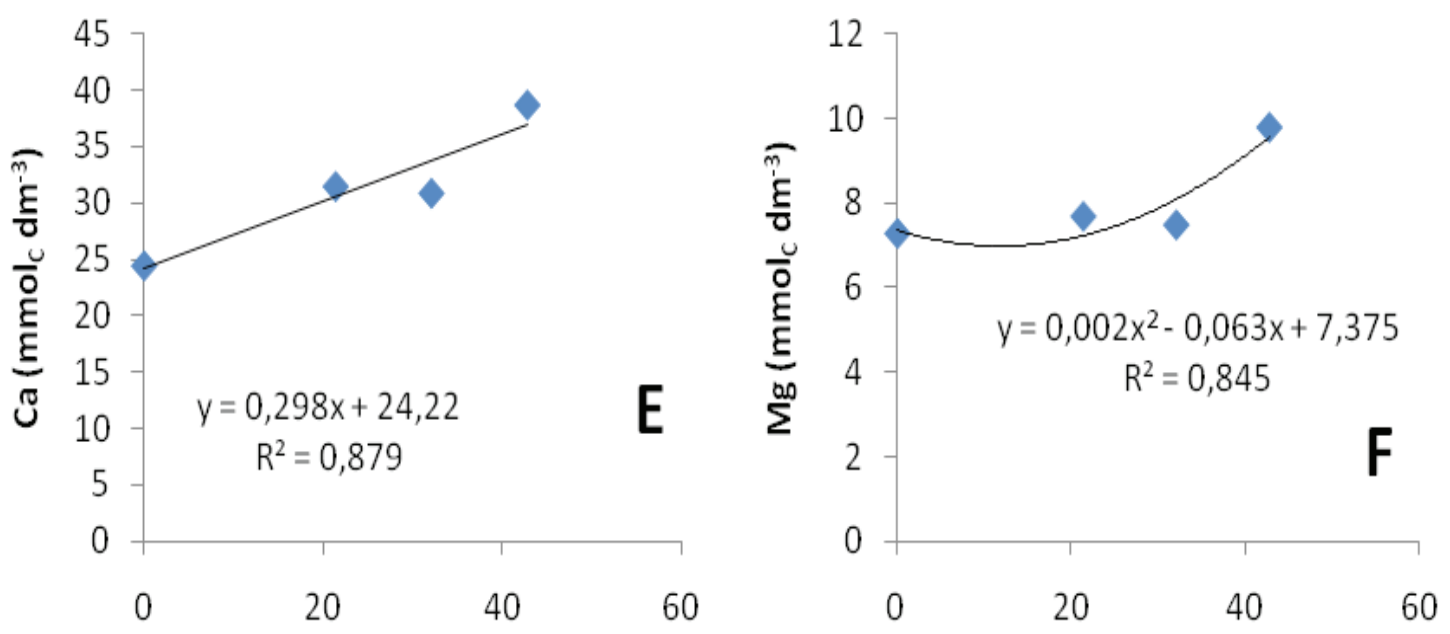

Doses de lodo compostado tha-1

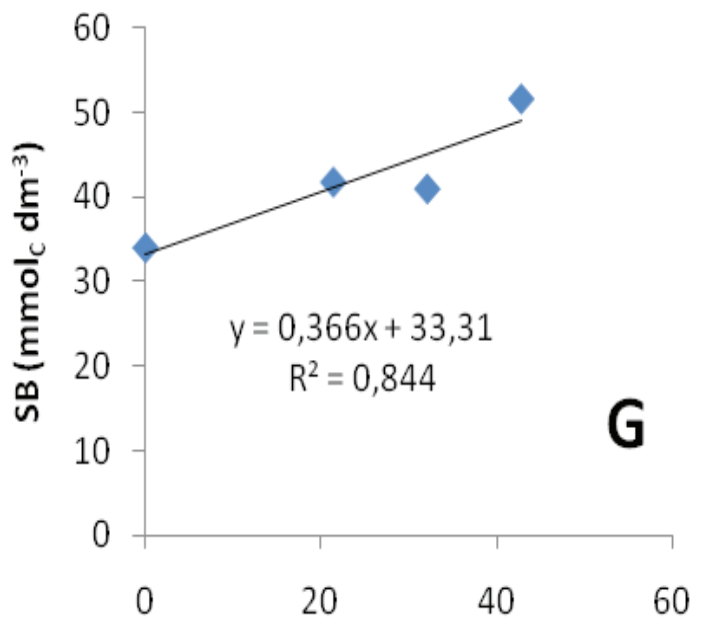

Doses de lodo compostado $\mathrm{tha}^{-1}$

Doses de lodo compostado tha-1

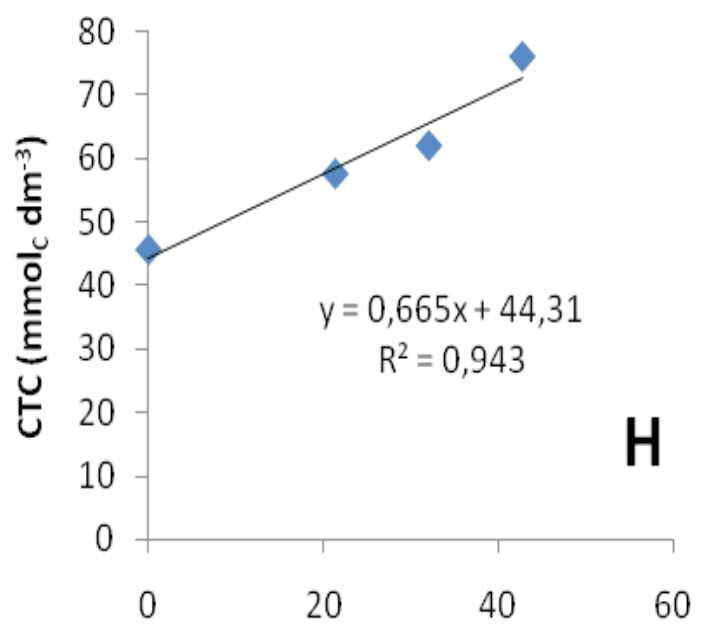

Doses de lodo compostado tha-1 


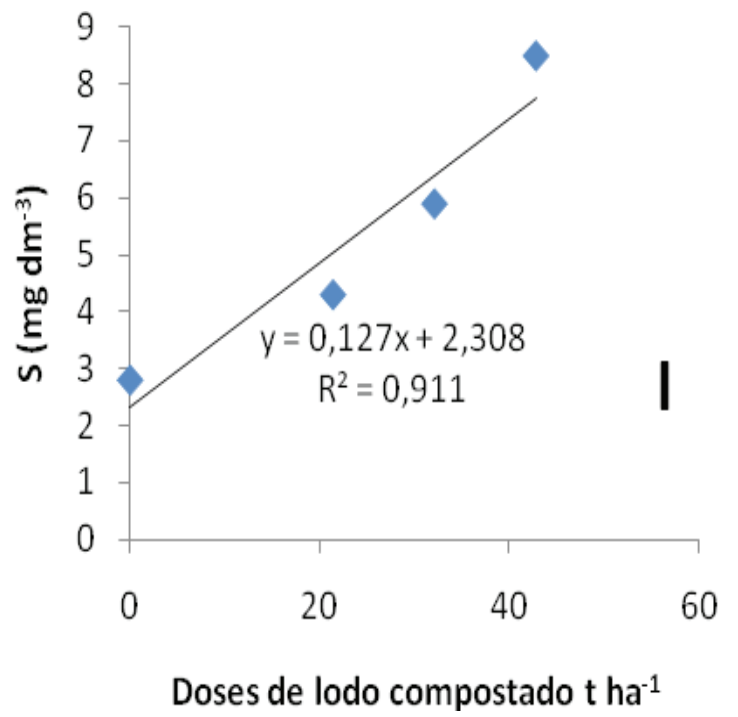

Fonte: Elaboração dos autores.

A V\% do solo não apresentou variação em nenhum dos tratamentos na profundidade de 0 a 20 cm (Tabela 5). Trannin, Silveira e Moreira (2008) não obtiveram diferenças significativas com 0 aumento de dose de lodo de esgoto na V\% do solo. Na profundidade de 20 a $40 \mathrm{~cm}$ não houve alteração entre os tratamentos apresentados na Tabela 6 e não houve influencia com o aumento da dose de lodo.

Tabela 5. Análise do solo 0 a $20 \mathrm{~cm}$.

\begin{tabular}{|c|c|c|c|c|c|c|c|c|c|c|c|}
\hline \multirow[t]{2}{*}{ Tra } & $\mathrm{pH}$ & MO & $\mathrm{P}$ & $\mathrm{H}+\mathrm{Al}$ & $\mathrm{K}$ & $\mathrm{Ca}$ & $\mathrm{Mg}$ & SB & CTC & \multirow{2}{*}{$\begin{array}{l}\mathrm{V} \\
\%\end{array}$} & \multirow{2}{*}{$\begin{array}{l}\mathrm{S} \\
\mathrm{mg} \mathrm{dm}{ }^{-3}\end{array}$} \\
\hline & $\mathrm{CaCl}_{2}$ & $\mathrm{~g} \mathrm{dm}^{-3}$ & $\mathrm{mg} \mathrm{dm}{ }^{-3}$ & \multicolumn{6}{|c|}{$\mathrm{mmol}_{\mathrm{c}} \mathrm{dm}^{-3}$} & & \\
\hline T0 & $6,1 \mathrm{a}$ & $6 \mathrm{~d}$ & $12 \mathrm{de}$ & $11 \mathrm{c}$ & 2,6 & $24 \mathrm{~b}$ & $7 b$ & $34 \mathrm{~b}$ & $46 \mathrm{~d}$ & 75 & $3 d$ \\
\hline $\mathrm{T} 1$ & $5,7 \mathrm{ab}$ & $8 \mathrm{~cd}$ & $9 \mathrm{e}$ & $14 \mathrm{bc}$ & 2,7 & $26 \mathrm{~b}$ & $9 a b$ & $37 \mathrm{~b}$ & $52 \mathrm{~cd}$ & 72 & $3 \mathrm{~d}$ \\
\hline $\mathrm{T} 2$ & $5,7 \mathrm{ab}$ & $10 \mathrm{c}$ & $17 \mathrm{~d}$ & $15 \mathrm{~b}$ & 2,6 & $27 a b$ & $8 \mathrm{ab}$ & $38 \mathrm{~b}$ & $53 \mathrm{bcd}$ & 71 & $3 \mathrm{~cd}$ \\
\hline T3 & $5,7 \mathrm{ab}$ & $11 \mathrm{c}$ & $23 \mathrm{c}$ & $16 \mathrm{~b}$ & 2,5 & $31 \mathrm{ab}$ & $8 b$ & $42 a b$ & $58 \mathrm{bc}$ & 72 & $4 c$ \\
\hline $\mathrm{T} 4$ & $5,4 \mathrm{~b}$ & $16 \mathrm{~b}$ & $34 \mathrm{~b}$ & $21 \mathrm{a}$ & 2,6 & $31 \mathrm{ab}$ & $7 \mathrm{~b}$ & $41 \mathrm{~b}$ & $62 \mathrm{~b}$ & 66 & $6 \mathrm{~b}$ \\
\hline T5 & $5,3 \mathrm{~b}$ & $22 \mathrm{a}$ & $44 \mathrm{a}$ & $24 \mathrm{a}$ & 3,1 & $39 a$ & $10 \mathrm{a}$ & $52 \mathrm{a}$ & $76 \mathrm{a}$ & 67 & $8 \mathrm{a}$ \\
\hline $\mathrm{F}$ & 3,86 & 30,6 & 73,65 & 16,82 & 1,1 & 3,31 & 2,29 & 3,02 & 13,5 & 1,6 & 43,7 \\
\hline M & 5,62 & 12,16 & 23,21 & 16,97 & 2,7 & 29,8 & 8,2 & 40,7 & 57,7 & 71 & 4,7 \\
\hline $\mathrm{CV}$ & 5,52 & 19,12 & 15,17 & 15,36 & 18 & 21,3 & 17,1 & 18,8 & 11,1 & 8,8 & 15,9 \\
\hline
\end{tabular}

Médias seguidas pelas mesmas letras não diferem entre si pelo teste de Duncan 5\% de probabilidade. T0 - sem N, T1 - $100 \%$ AM, T2 - 50\% AM + 50\% LE, T3 - 100\% LE, T4 - 150\% LE, T5 - 200\% LE. AM - Adubação mineral; LE - Lodo de esgoto.

Fonte: Elaboração dos autores. 
Tabela 6. Análise química do solo na profundidade de 20 a $40 \mathrm{~cm}$.

\begin{tabular}{llllllllllll}
\hline Trat & $\begin{array}{l}\mathrm{pH} \\
\mathrm{CaCl}_{2}\end{array}$ & $\begin{array}{l}\mathrm{MO} \mathrm{g} \mathrm{dm}^{-3} \\
\end{array}$ & $\mathrm{mg} \mathrm{dm}{ }^{-3}$ & $\mathrm{H}+\mathrm{Al}$ & $\mathrm{K}$ & $\mathrm{Ca}$ & $\mathrm{Mg}$ & $\mathrm{SB}$ & $\mathrm{CTC}$ & $\mathrm{V}$ & $\mathrm{S}$ \\
& & \multicolumn{7}{r}{$\mathrm{mmol}_{\mathrm{c}} \mathrm{dm}^{-3}$} \\
$\mathrm{~T} 0$ & $5,8 \mathrm{a}$ & $5,9 \mathrm{~b}$ & $11 \mathrm{~cd}$ & $13 \mathrm{c}$ & $1,9 \mathrm{~b}$ & $20 \mathrm{c}$ & 8 & $30 \mathrm{~b}$ & $43 \mathrm{c}$ & $68 \mathrm{ab}$ & $4 \mathrm{c}$ \\
$\mathrm{T} 1$ & $5,5 \mathrm{ab}$ & $7,7 \mathrm{~b}$ & $8 \mathrm{~d}$ & $17 \mathrm{bc}$ & $1,7 \mathrm{~b}$ & $20 \mathrm{c}$ & 8 & $30 \mathrm{~b}$ & $47 \mathrm{bc}$ & $63 \mathrm{ab}$ & $9 \mathrm{~b}$ \\
$\mathrm{~T} 2$ & $5,7 \mathrm{ab}$ & $7,6 \mathrm{~b}$ & $12 \mathrm{~cd}$ & $15 \mathrm{c}$ & $1,8 \mathrm{~b}$ & $24 \mathrm{bc}$ & 8 & $34 \mathrm{~b}$ & $48 \mathrm{bc}$ & $69 \mathrm{ab}$ & $4 \mathrm{c}$ \\
$\mathrm{T} 3$ & $5,8 \mathrm{a}$ & $9,6 \mathrm{ab}$ & $17 \mathrm{c}$ & $14 \mathrm{c}$ & $1,7 \mathrm{~b}$ & $26 \mathrm{ab}$ & 8 & $36 \mathrm{ab}$ & $50 \mathrm{~b}$ & $72 \mathrm{a}$ & $7 \mathrm{bc}$ \\
$\mathrm{T} 4$ & $5,34 \mathrm{~b}$ & $13,0 \mathrm{a}$ & $24 \mathrm{~b}$ & $20 \mathrm{ab}$ & $1,6 \mathrm{~b}$ & $24 \mathrm{bc}$ & 7 & $32 \mathrm{~b}$ & $52 \mathrm{~b}$ & $61 \mathrm{~b}$ & $9 \mathrm{~b}$ \\
$\mathrm{~T} 5$ & $5,33 \mathrm{~b}$ & $9,6 \mathrm{ab}$ & $32 \mathrm{a}$ & $22 \mathrm{a}$ & $2,5 \mathrm{a}$ & $30 \mathrm{a}$ & 8 & $40 \mathrm{a}$ & $63 \mathrm{a}$ & $65 \mathrm{ab}$ & $13 \mathrm{a}$ \\
$\mathrm{F}$ & 2,67 & 4,20 & 17,7 & 5,52 & 2,65 & 5,39 & 1,4 & 3,57 & 9,04 & 1,95 & 8,28 \\
$\mathrm{M}$ & 5,58 & 8,92 & 17,5 & 16,8 & 1,87 & 24 & 7,8 & 33,7 & 50 & 66,6 & 7,7 \\
$\mathrm{CV}$ & 5,63 & 29,91 & 27,8 & 19,7 & 23,4 & 15,1 & 15 & 14,3 & 9,75 & 9,41 & 33,2 \\
\hline
\end{tabular}

Médias seguidas pelas mesmas letras não diferem entre si pelo teste de Duncan 5\% de probabilidade. T0 - sem N, T1 - $100 \%$ AM, T2 - 50\% AM + 50\% LE, T3 - 100\% LE, T4 - 150\% LE, T5 - 200\% LE. AM - Adubação mineral; LE - Lodo de esgoto.

Fonte: Elaboração dos autores.

Em relação aos teores de $\mathrm{H}+\mathrm{Al}$ pode-se observar na Tabela 5 que o T4 e T5 foram superiores a todos os tratamentos e o $\mathrm{T} 0$ foi inferior a todos, o $\mathrm{H}+\mathrm{Al}$ esta relacionado com o $\mathrm{pH}$ quanto maior o $\mathrm{pH}$ em um mesmo solo menor será o $\mathrm{H}+\mathrm{Al}$. Observa-se na Figura $1 \mathrm{D}$ que com o aumento da dose de lodo ocorreu um incremento linear do $\mathrm{H}+\mathrm{Al}$. Trannin, Silveira e Moreira (2008) observou aumento do $\mathrm{H}+\mathrm{Al}$ com aumento da dose de lodo de esgoto. Todos os tratamentos que receberam alguma fonte de $\mathrm{N}$ mineral ou orgânico aumentaram os teores de $\mathrm{H}+\mathrm{Al}$. Na profundidade de 20 a $40 \mathrm{~cm}$ Verifica-se na Tabela 6 que para o $\mathrm{H}+\mathrm{Al}$ do $\mathrm{T} 1$ foi superior ao T0 e T3, com isso verificamos que a adubação nitrogenada mineral acarretou um aumento de $\mathrm{H}+\mathrm{Al}$ aumentando desta forma o Al em subsuperficie poderá ter problemas o sistema radicular das culturas sofrendo assim com falta de água porque a raiz da planta não vai penetrar em uma maior profundidade. À medida que foi aumentando a dose de lodo aumentou linearmente o $\mathrm{H}+\mathrm{Al}$ como mostra a Figura 2 D. Comparando 0 a $20 \mathrm{~cm}$ com 20 a $40 \mathrm{~cm}$ pode-se verificar que o comportamento foi da mesma forma que o $\mathrm{pH}$ do solo, ou seja os tratamentos que não foram aplicados o lodo de esgoto apresentaram os teores mais elevados em 20 a $40 \mathrm{~cm}$ e onde foi aplicado o lodo apresentaram superiores os tratamentos de 0 a $20 \mathrm{~cm}$, pelo fato que na superfície do solo tem mais influencia da aplicação do lodo.

$\mathrm{O}$ teor de $\mathrm{K}$ no solo não houve alteração em função dos tratamentos, tendo em vista que o lodo de esgoto apresenta teor muito baixo deste elemento para todos os tratamentos foram feitos uma suplementação igual de $\mathrm{K}$ de acordo com a necessidade da cultura. Comparando com a análise de solo inicial verifica-se que o $\mathrm{K}$ até aumentou, mas isto foi decorrente das quantidades altas colocadas de cloreto de potássio no plantio das culturas e este elemento foi muito pouco exportado em relação à quantidade que foi colocado. Ou seja, apresentou um balanço final positivo entre todos os tratamentos. Foram padronizados os teores de $\mathrm{K}$ para todos os tratamentos, com pode ser visto na análise de solo inicial o $\mathrm{K}$ estava em um nível adequado. $\mathrm{Na}$ profundidade de 20 a $40 \mathrm{~cm}$ o tratamento de maior dose obteve um aumento de K (Tabela 6). Observase na Figura 2 E que com o aumento da dose de lodo diminuiu o teor de $\mathrm{K}$, devido ao aumento de $\mathrm{H}$ e $\mathrm{Al}$ e posteriormente ocorreu um aumento no teor de $\mathrm{K}$ decorrente do aumento das cargas negativas do solo. Aos 0-20 cm apresentaram-se valores superiores de K em relação a 20 a $40 \mathrm{~cm}$ para todos os tratamentos. Segundo Raij et al. (2001) todos os tratamentos apresentam teores médios. 
Verifica-se que para os teores de Ca na Tabela 5 que o T5 foi superior estatisticamente que os tratamentos que não foram aplicados lodo (T0, T1 e T2) e em relação ao aumento da dose de lodo houve um incremento linear para o Ca como mostra a Figura $1 \mathrm{E}$, porem o fator que contribuiu para este aumento foi a calagem que foi feito depois da $3^{\mathrm{a}}$ aplicação nas parcelas que houve necessidade (Tabela 3). Comparando com a análise de solo inicial pode-se reparar que os teores de $\mathrm{Ca}$ aumentaram para todos os tratamentos, isto é decorrente a aplicação de calcário e as adubações com superfosfato simples que contem $\mathrm{Ca}$. Segundo Raij et al. (2001) todos os valores de Ca apresentam altos. Na profundidade de 20 a $40 \mathrm{~cm}$ observase na Tabela 6 que o T3 foi superior ao T0 e T1. Houve um incremento no teor de Ca no solo na profundidade de 20 a $40 \mathrm{~cm}$ em função do aumento da dose de lodo. Para todos os tratamentos 20 a 40 $\mathrm{cm}$ apresentou-se inferior em relação a 0 a $20 \mathrm{~cm}$. Segundo Raij et al. (2001) todos os tratamentos apresentaram teores altos.

Figura 2. Análises do solo de 20 a $40 \mathrm{~cm}$ de profundidade em função da dose de lodo compostado.

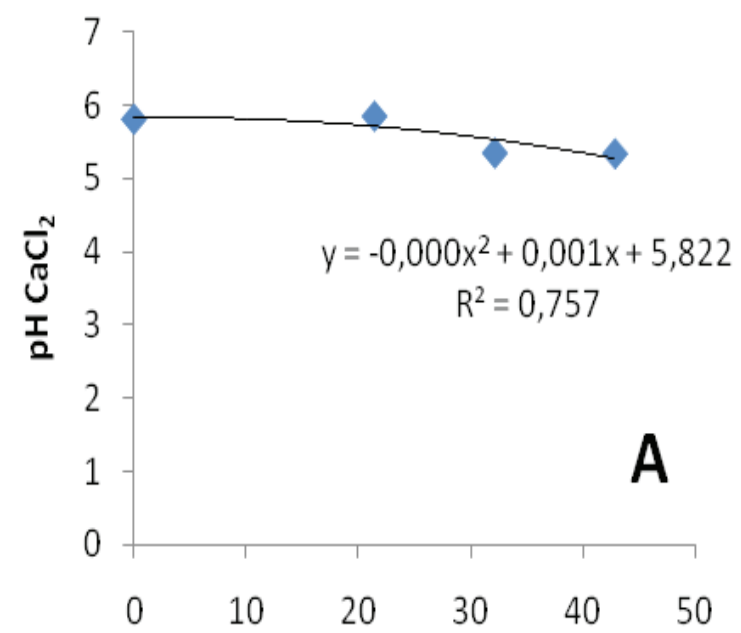

Dose de lodo compostado t ha-1

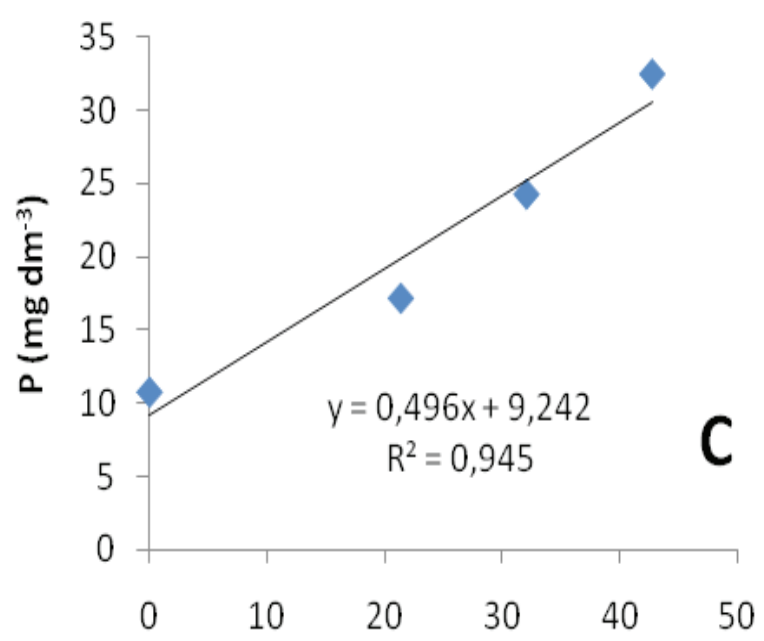

Dose de lodo compostado tha-1

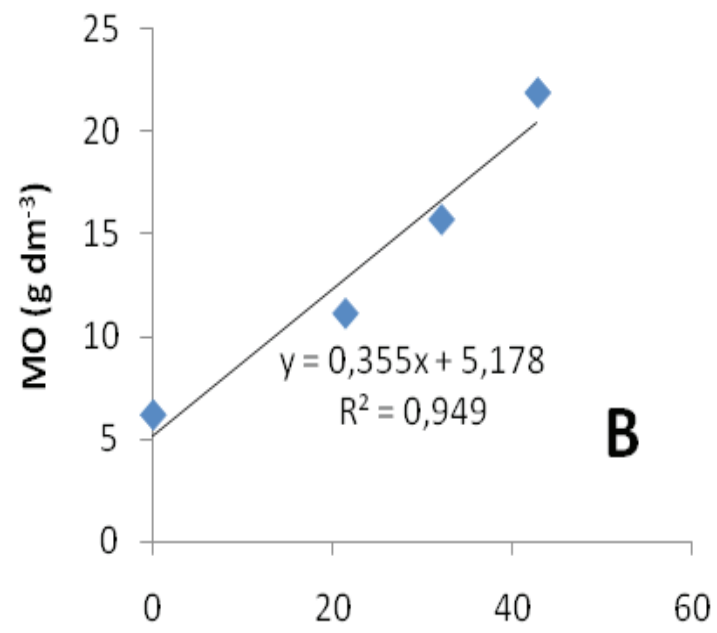

Doses de lodo compostado tha-1

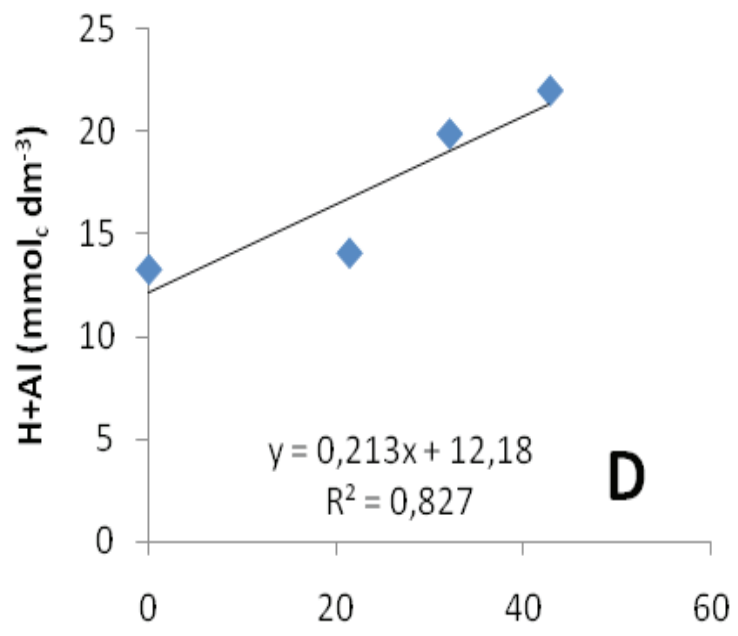

Dose de lodo compostado $\mathrm{t}$ ha-1 


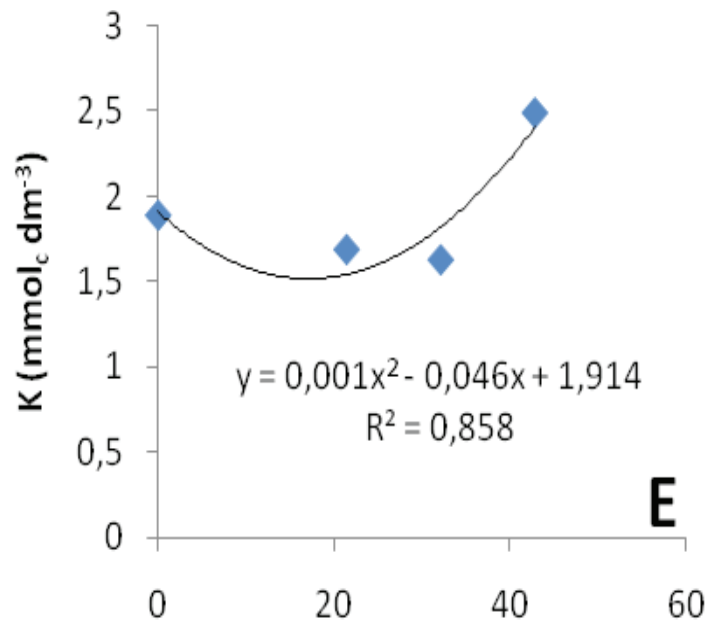

Dose de lodo compostado tha-1

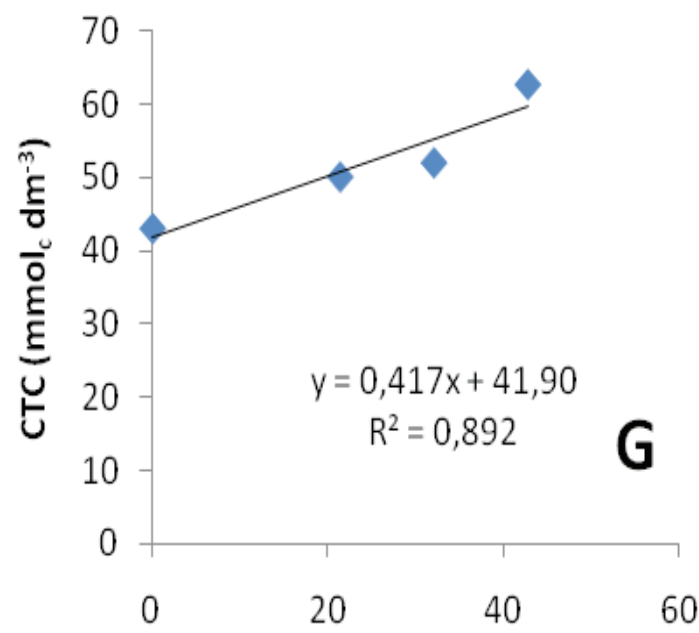

Dose de lodo compostado t ha-1

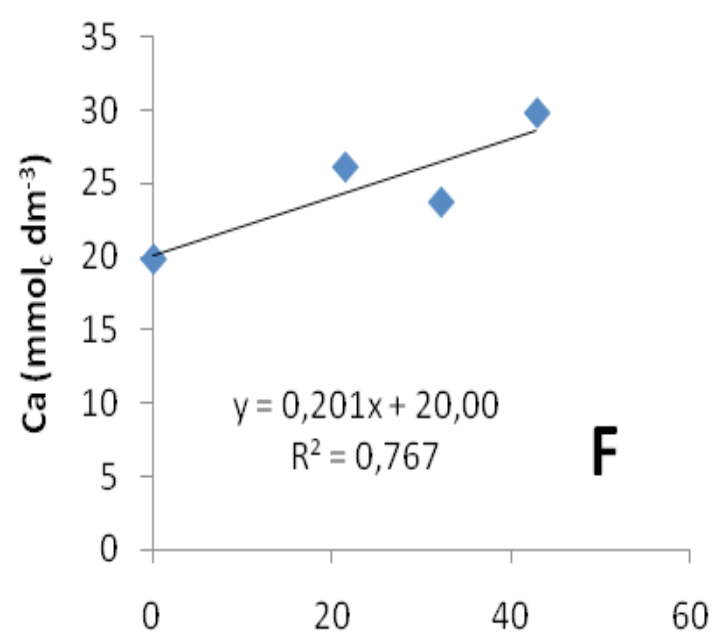

Dose de lodo compostado $\mathrm{tha}^{-1}$

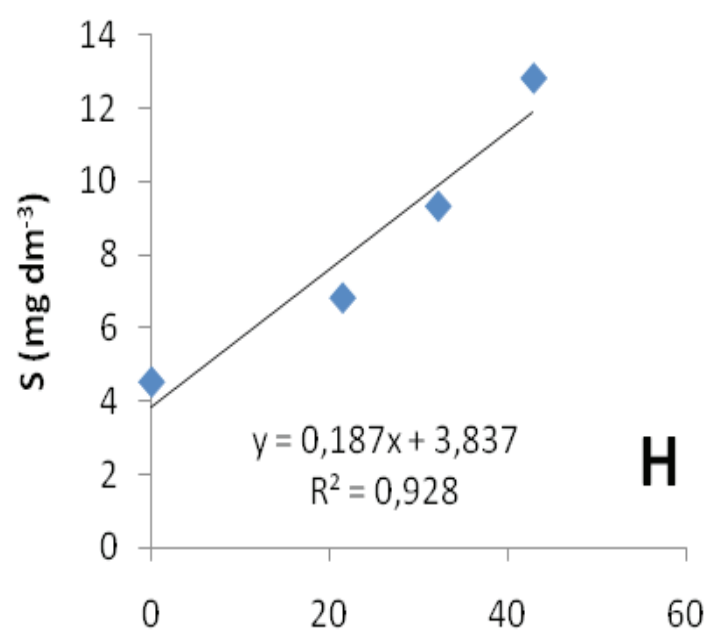

Dose de lodo compostado $\mathrm{tha}^{-1}$

Fonte: Elaboração dos autores.

Quanto ao Mg observa-se na Tabela 5 que o T5 foi estatisticamente superior ao T0, T3 e ao T4. Os valores encontrados nos tratamentos são classificados segundo Raij et al. (2001) com os tratamentos (T0, T2, T3 e T4) apresentam teores médio de $\mathrm{Mg}$ e os tratamentos (T1 e T5) apresentaram teores altos. Os tratamentos que não receberam lodo a \% na CTC de $\mathrm{Mg}$ apresentou-se superior onde foi lodo, isto é decorrente ao aumento do teor de matéria orgânica do lodo que também houve um aumento da CTC do solo. Quanto ao $\mathrm{Mg}$ não ocorreu variação entre os tratamentos. As médias de todos os tratamentos apresentaram teores médios de Mg, segundo Raij et al. (2001).

Para a SB o tratamento T5 apresentou-se estatisticamente superior aos tratamentos T0, T1, T2, T3 e T4. Verifica-se na Figura $1 \mathrm{G}$ que com o aumento da dose de lodo ocorreu um incremento linear na $\mathrm{SB}$, o $\mathrm{Ca}$ e o $\mathrm{Mg}$ foram os responsáveis para este incremento da SB. Comparando os resultados de solo inicial houve um incremento na SB para todos os tratamentos. Quanto a SB não ocorreu diferenças significativas em relação aos tratamentos apresentado na Tabela 6 .

A CTC do solo foi aumentada decorrente do 
aumento da dose de lodo de esgoto acompanhando o aumento da matéria orgânica do solo tendo em vista que acompanharam o aumento da Matéria orgânica do solo aumentando desta maneira as cargas negativas do solo (Figura $1 \mathrm{H}$ ) (Tabela 5). Observa-se que houve um aumento da CTC do solo em relação ao solo original nos tratamentos que receberam $\mathrm{N}$ ou mineral ou orgânico. Silva et al. (2001) observaram que com o aumento da dose de lodo de esgoto foi aumentado a CTC do solo em uma reta linear. Trannin, Silveira e Moreira (2008) observaram que com aumento da dose de lodo de esgoto houve um incremento da CTC do solo. Silva, Boareto e Berton (1995) verificaram que o aumento dos teores de matéria orgânica do solo contribui para o aumento da CTC, mediante a geração de cargas negativas devido à alta concentração de matéria orgânica que o lodo possui. $\mathrm{Na}$ profundidade de 20 a $40 \mathrm{~cm}$ os tratamentos (T3, T4 e T5) foram superiores ao tratamento que não recebeu N (T0) e o T5 foi superior a todos os tratamentos. $\mathrm{O}$ aumento da dose de lodo proporcionou um incremento na CTC do solo. Na profundidade superficial (0 a 20 $\mathrm{cm}$ ) pode-se observar que a CTC para todos os tratamentos apresentaram superiores em relação a 20 a $40 \mathrm{~cm}$. O aumento da CTC foi decorrente ao aumento da Matéria orgânica e o $\mathrm{pH}$ diminuiu devido a nitrificação do $\mathrm{N}$ do lodo deixando desta maneira H livre na solução do solo.

Observa-se na Tabela 5 e Figura 1 B que com o aumento da dose de lodo de esgoto houve um incremento no teor de matéria orgânica do solo. Hortenstine e Rothwell (1972) verificaram aumentos de 41 e 169\% nos teores de C orgânicos de um solo degradado por mineração, 24 meses após a aplicação de 35 e $70 \mathrm{Mg}^{-1}$ de composto de lixo, respectivamente. Oliveira et al. (2002) concluíram que aplicações anuais e sucessivas de composto de lixo, em doses superiores a $20 \mathrm{Mg}^{-}$ 1, aumentaram os teores de $\mathrm{C}$ orgânico. A adição de lodo em doses de $50 \mathrm{Mg} \mathrm{ha}^{-1}$ aumentou o teor de C orgânico, como observado por Melo et al. (1994), que, ao avaliarem as frações da matéria orgânica do solo de um latossolo cultivado com cana-deaçúcar, com adição de 4, 16, $32 \mathrm{Mg} \mathrm{ha}^{-1}$ de lodo, verificaram que apenas a maior dose promoveu aumento significativo no $\mathrm{C}$ do solo. Soares et al. (2008) trabalhando com lodo de esgoto em seis aplicações para a cultura do milho em dosagens acumulativas de $0,30,60,120$ e 240 t ha $^{-1}$ de lodo de esgoto observou um aumento linear dos teores de $\mathrm{C}$ orgânico. Quanto os teores de matéria orgânica nos 20 a $40 \mathrm{~cm}$ podem observar que o T4 foi superior ao T0, T1 e T2. A matéria orgânica foi aumentando com o aumenta da dose de lodo ate a dosagem do T4 e em seguida ocorreu um decréscimo. Estes valores foram inferiores dos encontrados na profundidade de 0 a $20 \mathrm{~cm}$. Dias (2005) observou que houve uma tendência de aumento do teor de carbono no solo na profundidade de 20 a $40 \mathrm{~cm}$ em função da dose de lodo de esgoto após o $6^{\circ}$ ano de aplicação.

Para o P observa-se na Tabela 5 e Figura $1 \mathrm{C}$ que com o aumento das doses de lodo de esgoto foi aumentando significativamente os teores de $\mathrm{P}$ no solo. Marques (1996) observou que o teor de P-resina aumentou linearmente com a dose de lodo de esgoto da ETE de Barueri (SP) aplicada a um Latossolo Vermelho Distrofico textura média, o que também foi verificado por Silva et al. (1998) em Nitossolo, ambos cultivados com cana de açúcar em condições de campo. Comparando estes dados de $\mathrm{P}$ com os iniciais verifica-se que houve um aumento no solo para os tratamentos T3, T4 e T5. Segundo Raij et al. (2001) os tratamentos que não foram aplicados lodo de esgoto apresentaram teores baixo de $\mathrm{P}$ e os tratamentos T2, T3 e T4 apresentaram um teor de P médio e o T5 já apresentou um teor alto de P no solo. Segundo Mello (1980) este aumento é devido a adição de material orgânico ao solo que promove aumento na disponibilidade de $\mathrm{P}$ pela liberação de P orgânico durante o processo de mineração, dissolução de fosfatos insolúveis em água pela ação de ácidos carbônicos, provenientes da decomposição de material orgânico, formação de complexos fosfo-húmico facilmente assimiláveis, formação de fosfatos orgânicos mais fracamente retidos no solo, 
revestimento superficial das partículas de argilas, evitando contato direto das mesmas com o fosfato. Kitamura et al. (2008) observou aumento no teor de P com a aplicação de lodo de esgoto a aplicação do lodo funcionou como uma adubação corretiva de P. A decomposição do lodo de esgoto gera agentes complexantes que facilitam a solubilização, no solo, de fosfato combinado a ferro e alumínio, bem como libera, gradualmente, nutrientes essenciais as plantas, como N, P, S (FERNANDES et al., 1996). Barbosa, Tavares Filho e Fonseca (2002) verificaram aumento nos teores de $\mathrm{P}$ à medida que aumentaram as doses de lodo de esgoto, acima de $24 \mathrm{t} \mathrm{ha}^{-1} \mathrm{em}$ relação a analise inicial do solo. Estes resultados são semelhantes aos encontrados por Silva et al. (1998). Na profundidade de 20 a $40 \mathrm{~cm}$ observase na Tabela 6 que o T3 apresentou um teor de P superior aos tratamentos que não foram aplicados lodo (T0 e T1). Com o aumento da dose de lodo ocorreu um incremento linear de $\mathrm{P}$ na profundidade de 20 a $40 \mathrm{~cm}$ como mostra a Figura 2 C. Segundo Raij et al. (2001) o T0, T1 e T2 apresentam valores baixos e o T3, T4 e T5 apresentam valores médios. Verificam que na profundidade de 0 a $20 \mathrm{~cm}$ o teor de $\mathrm{P}$ foi superior para todos os tratamentos do que na profundidade de 20 a $40 \mathrm{~cm}$ isto pode ser explicado que o $\mathrm{P}$ se movimenta muito lentamente no perfil do solo.

Quanto ao S observa-se na Tabela 5 que o T5 foi superior a todos os outros tratamentos. O T4 foi superior aos tratamentos (T0, T1, T2, T3). O T3 foi superior ao $\mathrm{T} 0 \mathrm{e} \mathrm{T} 1$. À medida que foi aumentando a dose de lodo foi aumentando linearmente o teor de $\mathrm{S}$ no solo (Figura $1 \mathrm{I})$. Os valores encontrados, para $\mathrm{S}$ em T0, T1 e T2 são classificados segundo Raij et al. (2001) como teores baixos e os tratamentos T3, T4 e $\mathrm{T} 5$ apresentam teores médios de $\mathrm{S}$. Na profundidade de 20 a $40 \mathrm{~cm}$ observa-se que o T1 foi superior ao
T0 e T2. À medida que foi aumentando a dose de lodo aumentou o teor de S (Figura $2 \mathrm{H}$ ). Segundo Raij et al. (2001) somente o T5 apresentou teor alto de $\mathrm{S}$ os demais tratamentos apresentaram teores médios. Observa-se que para todos os tratamentos os teores de $\mathrm{S}$ foram superiores na profundidade de 20 a $40 \mathrm{~cm}$ em relação a 0 a $20 \mathrm{~cm}$, ou seja, o $\mathrm{S}$ foi lixiviado no perfil do solo.

$\mathrm{Na}$ Tabela 7 observa-se que para o teor de B o tratamento T5 apresentou superior a todos os tratamentos. O tratamento T4 apresentou-se superior aos tratamentos T0, T1, T2 e T3. Os tratamentos T2 e T3 apresentaram iguais estatisticamente e superior aos tratamentos que não foram aplicados lodo (T0 e T1). Os tratamentos que não foram aplicados lodo não diferiram. Com o aumento da dose de lodo ocorreu um incremento no teor de B no solo linearmente como mostra a Figura 3 A. Segundo Raij et al. (2001) os tratamentos T0, T1 e T2 apresentam teores baixos de $\mathrm{B}$ e os tratamentos $\mathrm{T} 3, \mathrm{~T} 4$ e T5 apresentam teores médios de B. Ao verificar-se o teor inicial de B verifica-se que todos os tratamentos apresentaram um teor superior ao inicial isto pode ser explicado devido à adubação com acido bórico nos três cultivos de girassol devido ser uma cultura que necessita de boa quantidade de B, então como não foi exportado pelo grão do girassol o $\mathrm{B}$ permaneceu no solo. Para a profundidade de 20 a $40 \mathrm{~cm}$ na Tabela 8 observa-se que o T3 obteve um maior teor de B que o T0 e T1. O T4 foi superior que o T3 e o T5 superior que o T4. Com o aumento da dose de lodo ocorreu um aumento linear no teor de B (Figura 4 A). Segundo Raij et al. (2001) os tratamentos T4 e T5 apresentam teores médios de B e os demais tratamentos apresentam teores baixos de B. Observa-se que os teores de B na profundidade de 20 a $40 \mathrm{~cm}$ esta inferior dos encontrados de 0 a $20 \mathrm{~cm}$. 
Tabela 7. Análise química de micronutrientes do solo 0 a $20 \mathrm{~cm}$.

\begin{tabular}{llllll}
\hline Tratamentos & $\mathrm{B}$ & $\mathrm{Cu}$ & $\mathrm{Fe}$ & $\mathrm{Mn}$ & $\mathrm{Zn}$ \\
& & \multicolumn{2}{c}{$\mathrm{mg} \mathrm{dm}^{-3}$} & & \\
\hline T0 & $0,15 \mathrm{~d}$ & $1,41 \mathrm{e}$ & $16,1 \mathrm{e}$ & $5,4 \mathrm{c}$ & $1,68 \mathrm{~d}$ \\
T1 & $0,17 \mathrm{~d}$ & $1,43 \mathrm{e}$ & $20,4 \mathrm{de}$ & $5,7 \mathrm{c}$ & $1,20 \mathrm{~d}$ \\
T2 & $0,19 \mathrm{c}$ & $2,50 \mathrm{~d}$ & $33,9 \mathrm{~d}$ & $7,9 \mathrm{~b}$ & $6,88 \mathrm{~d}$ \\
T3 & $0,21 \mathrm{c}$ & $3,48 \mathrm{c}$ & $63,8 \mathrm{c}$ & $7,1 \mathrm{bc}$ & $14,95 \mathrm{c}$ \\
T4 & $0,24 \mathrm{~b}$ & $5,44 \mathrm{~b}$ & $93,5 \mathrm{~b}$ & $8,6 \mathrm{~b}$ & $26,50 \mathrm{~b}$ \\
T5 & $0,28 \mathrm{a}$ & $6,34 \mathrm{a}$ & $126,9 \mathrm{a}$ & $10,4 \mathrm{a}$ & $45,85 \mathrm{a}$ \\
F & 50,15 & 96,22 & 81,33 & 10,31 & 57,75 \\
Média & 0,21 & 3,43 & 59,11 & 7,52 & 16,18 \\
CV & 7,39 & 13,77 & 18,55 & 17,43 & 31,60 \\
\hline
\end{tabular}

Médias seguidas pelas mesmas letras não diferem entre si pelo teste de Duncan 5\% de probabilidade. T0 - sem N, T1 - $100 \%$ AM, T2 - 50\% AM + 50\% LE, T3 - 100\% LE, T4 - 150\% LE, T5 - 200\% LE. AM - Adubação mineral; LE - Lodo de esgoto.

Fonte: Elaboração dos autores.

Tabela 8. Analise química de solo 20 a $40 \mathrm{~cm}$ de micronutrientes após o trigo.

\begin{tabular}{|c|c|c|c|c|c|}
\hline \multirow[t]{2}{*}{ Tratamentos } & \multirow[t]{2}{*}{ B } & \multirow{2}{*}{$\mathrm{Cu}$} & \multirow{2}{*}{$\mathrm{Fe} \mathrm{mg} \mathrm{dm}^{-3}$} & \multirow{2}{*}{$\mathrm{Mn}$} & \multirow[t]{2}{*}{$\mathrm{Zn}$} \\
\hline & & & & & \\
\hline T0 & $0,15 \mathrm{~d}$ & $1,49 \mathrm{~b}$ & $17,2 \mathrm{~d}$ & $4,4 \mathrm{c}$ & $1,88 \mathrm{c}$ \\
\hline $\mathrm{T} 1$ & $0,16 \mathrm{~d}$ & $1,44 \mathrm{~b}$ & $18,3 \mathrm{~d}$ & $3,9 \mathrm{c}$ & $1,38 \mathrm{c}$ \\
\hline $\mathrm{T} 2$ & $0,17 \mathrm{~cd}$ & $2,33 \mathrm{~b}$ & $32,9 \mathrm{~cd}$ & $6,4 \mathrm{ab}$ & $6,11 \mathrm{c}$ \\
\hline $\mathrm{T} 3$ & $0,19 \mathrm{c}$ & $2,29 \mathrm{~b}$ & $40,3 \mathrm{c}$ & $5,2 \mathrm{bc}$ & $7,13 \mathrm{c}$ \\
\hline $\mathrm{T} 4$ & $0,22 \mathrm{~b}$ & $4,09 \mathrm{a}$ & $70,7 \mathrm{~b}$ & $6,8 \mathrm{a}$ & $13,55 \mathrm{~b}$ \\
\hline T5 & $0,25 \mathrm{a}$ & $4,63 \mathrm{a}$ & $95,6 \mathrm{a}$ & $7,6 \mathrm{a}$ & $26,00 \mathrm{a}$ \\
\hline $\mathrm{F}$ & 18,60 & 21,47 & 23,46 & 9,14 & 24,99 \\
\hline Média & 0,19 & 2,71 & 45,85 & 5,72 & 9,34 \\
\hline $\mathrm{CV}$ & 10,10 & 23,84 & 31,42 & 18,57 & 44,36 \\
\hline
\end{tabular}

Médias seguidas pelas mesmas letras não diferem entre si pelo teste de Duncan 5\% de probabilidade. T0 - sem N, T1 - $100 \%$ AM, T2 - 50\% AM + 50\% LE, T3 - 100\% LE, T4 - 150\% LE, T5 - 200\% LE. AM - Adubação mineral; LE - Lodo de esgoto.

Fonte: Elaboração dos autores.

Figura 3. Análise de micronutrientes do solo de 0 a $20 \mathrm{~cm}$ de profundidade em função da dose de lodo compostado.

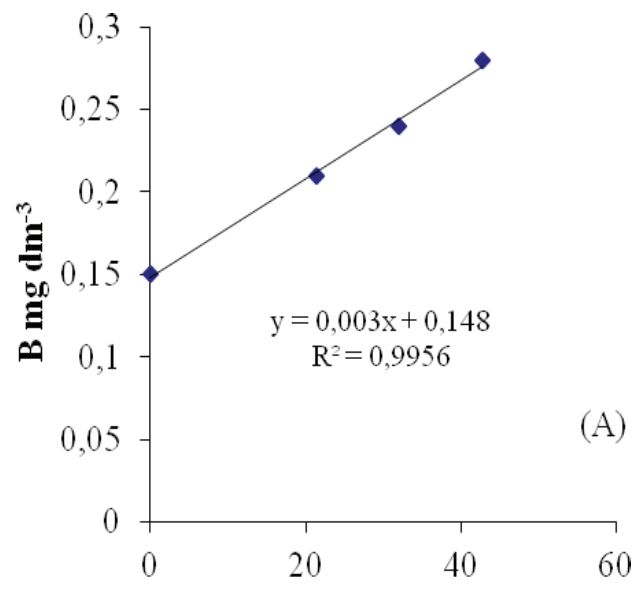

Doses de lodo compostado tha-1

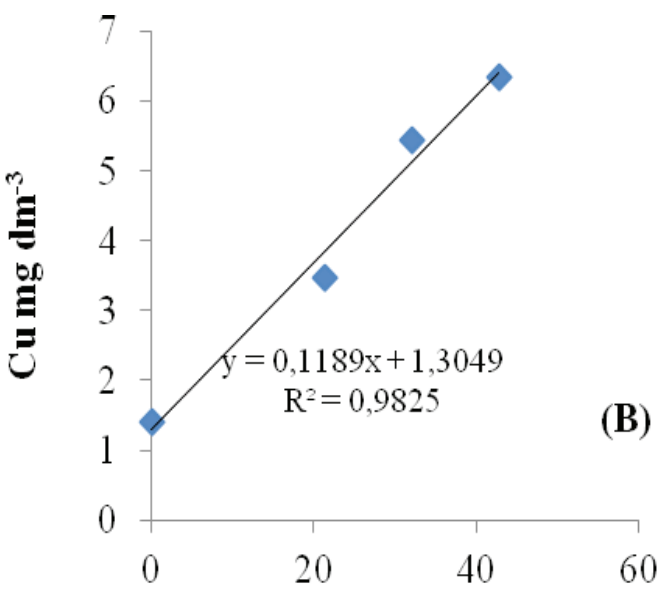

Doses de lodo compostado $\mathrm{ha}^{-1}$ 

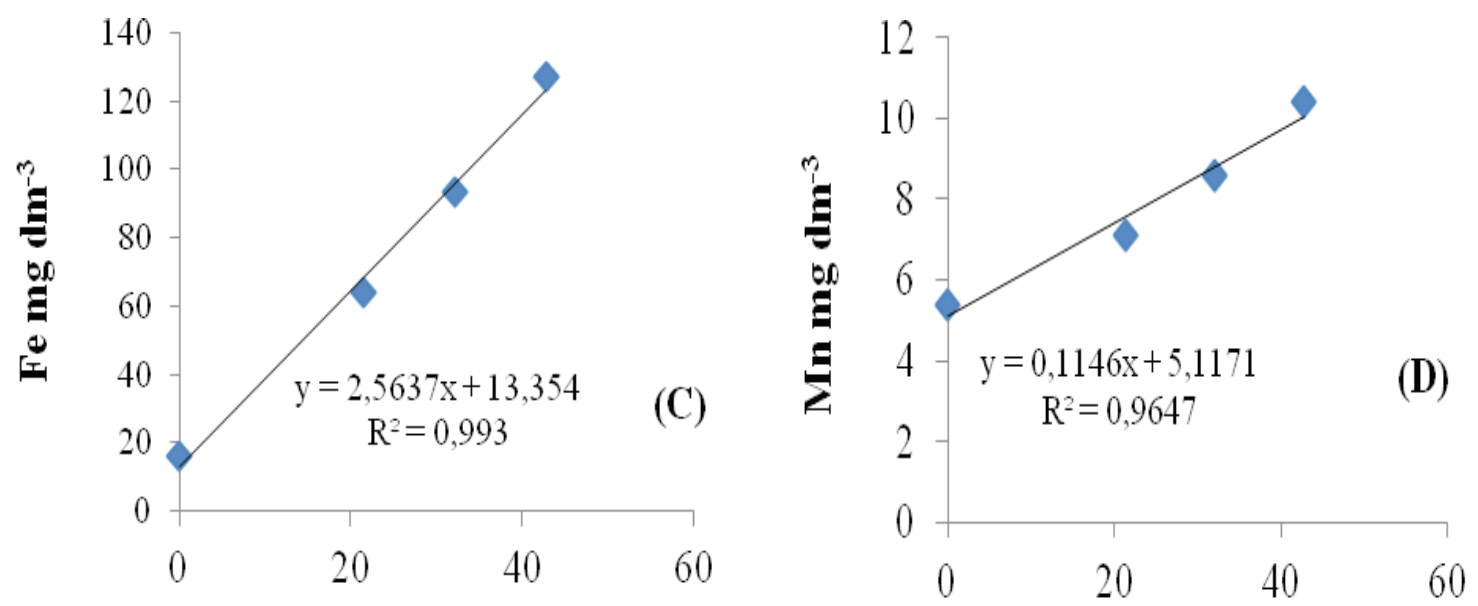

Doses de Lodo compostado t ha ${ }^{-1}$

Doses de Lodo compostado tha-1

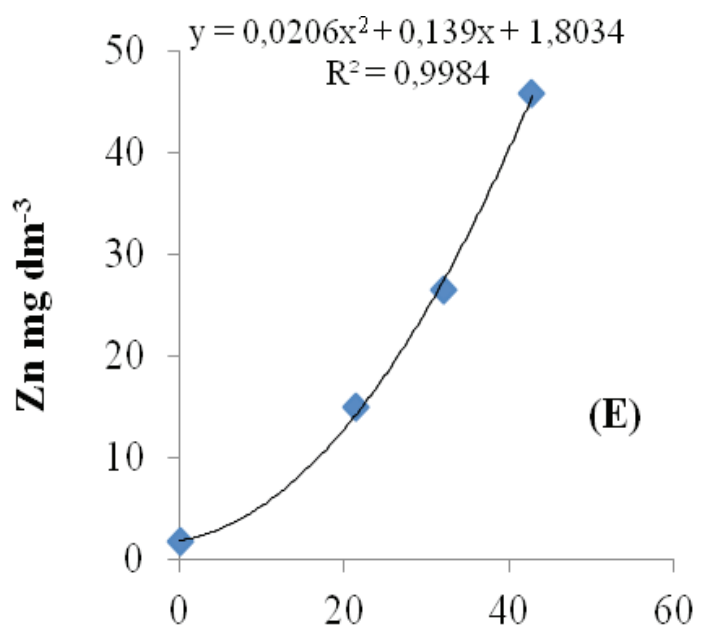

Doses de Lodo compostado t ha-1

Fonte: Elaboração dos autores.

Figura 4. Analises de micronutrientes do solo de 20 a $40 \mathrm{~cm}$ em função do aumento da dose de lodo de esgoto.
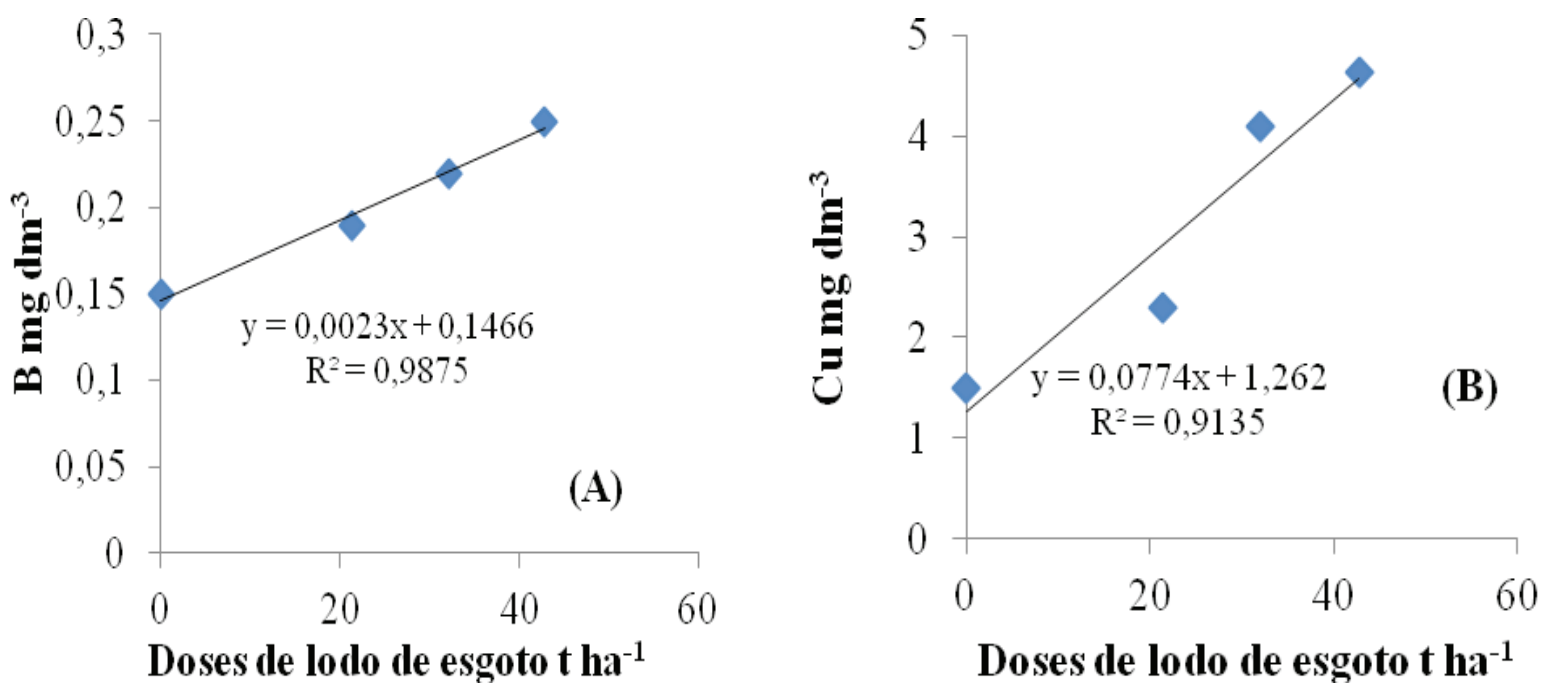

Doses de lodo de esgoto t ha' 

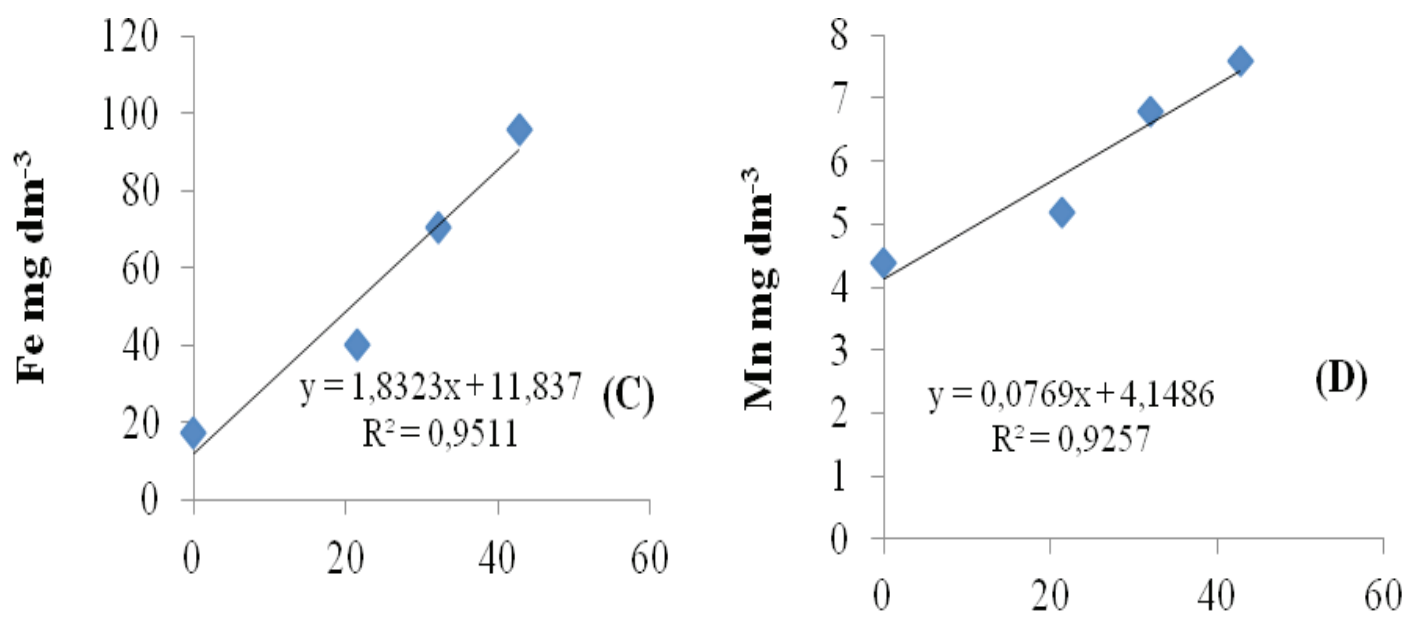

Doses de lodo de esgoto $t \mathrm{ha}^{-1}$

\section{Doses de lodo de esgoto $t \mathrm{ha}^{-1}$}

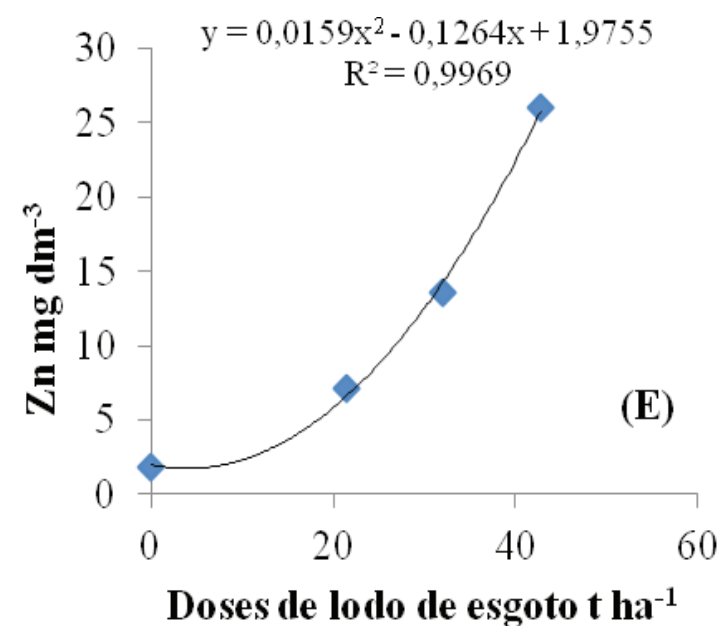

Fonte: Elaboração dos autores.

Observa-se na Tabela 7 que para o $\mathrm{Cu}$ quando foi aumentando a dosagem de lodo de esgoto foi aumentando os teores de $\mathrm{Cu}$ no solo. Onde não foi aplicado lodo estes teores não variaram. A medida que foi aumentando a dose de lodo ocorreu um incremento no teor de $\mathrm{Cu}$ linearmente como mostra a Figura 3 B. Segundo Raij et al. (2001) todos os valores apresentaram altos teores de $\mathrm{Cu}$, porem segundo a USEPA (1996) todos os valores estão abaixo dos considerados tóxicos de $\mathrm{Cu}$ no solo. Comparando os teores iniciais de $\mathrm{Cu}$ no solo observase que todos os tratamentos aumentaram os teores até mesmo onde não foi aplicado lodo de esgoto, isto pode ser explicado devido a aplicação no feijão e no trigo de fungicidas que continham $\mathrm{Cu}$ e o lodo de esgoto apresenta um bom teor deste mineral. $\mathrm{Na}$ profundidade de 20 a $40 \mathrm{~cm}$ verificam-se na Tabela 8 que os tratamentos T2 e T3 apresentaram teores de $\mathrm{Cu}$ superiores aos demais tratamentos. Na Figura 4 observa-se que com o aumento da dose de lodo aumentou linearmente o teor de $\mathrm{Cu}$ na profundidade de 20 a $40 \mathrm{~cm}$. Segundo Raij et al. (2001) todos os tratamentos apresentaram altos teores deste elemento. Os tratamentos onde não foram aplicados lodo (T0 e T1) apresentaram teores mais elevados na profundidade de 20 a $40 \mathrm{~cm}$ em relação a profundidade de 0 a $20 \mathrm{~cm}$. Já os tratamentos que foram aplicados lodo de esgoto (T2, T3, T4, T5) os teores maiores de $\mathrm{Cu}$ se encontraram em 0 a 20 $\mathrm{cm}$, tendo em vista que o lodo de esgoto aplicado 
superficialmente contem $\mathrm{Cu}$ e este não foi lixiviado devido as cargas negativas da matéria orgânica proveniente do lodo reteve o $\mathrm{Cu}$ na superfície. Oliveira e Mattiazo (2001) constataram que após duas aplicações em anos sucessivos de composto de lixo urbano, não há evidencias de movimentação, no perfil do solo de $\mathrm{Cu}$. A imobilidade do $\mathrm{Cu}$ também foi observada por Williams et al. (1987), Dowdy et al. (1991), Chino et al. (1992) e Oliveira e Mattiazo (2001) em solos tratados com elevadas doses de lodo de esgoto e monitorados por períodos de respectivamente, 9,14, 12 e 2 anos.

Observa-se na Tabela 7 e Figura $3 \mathrm{C}$ que o Fe se comportou da mesma forma que o $\mathrm{Cu}$ entre os tratamentos e em função do aumento da dose de lodo. Trannin (2004) obteve aumento do teor de Fe no solo em função da dose de lodo de esgoto aplicado. Segundo Raij et al. (2001) todos os tratamentos apresentaram teores altos de Fe. $\mathrm{Na}$ profundidade de 20 a $40 \mathrm{~cm}$ verifica-se na Tabela 8 que os tratamentos que foram aplicados lodo somente o lodo como fonte de N (T3, T4 e T5) apresentaram um teor de Fe superiores aos tratamentos que não foram aplicados lodo (T0 e T1) e o T4 foi superior que o T3 e o T5 superior que o T4. A medida que aumentou a dose de lodo aumentou o teor de Fe no solo linearmente nesta profundidade como se observa na Figura 4 C. Segundo Raij et al. (2001) para todos os tratamentos os teores de Fe apresentaram altos. Somente no tratamento que não foi aplicado $\mathrm{N}$ (T0) apresentou um teor de Fe maior na profundidade de $20 \mathrm{a} 40 \mathrm{~cm}$ em relação à profundidade de 0 a $20 \mathrm{~cm}$, os demais tratamentos apresentaram teores maiores na profundidade de 0 a $20 \mathrm{~cm}$ em relação a profundidade de 20 a $40 \mathrm{~cm}$.

Para os teores de Mn verifica-se na Tabela 7 que o T5 apresentou um teor mais elevado que os outros tratamentos. O T4 e o T2 foram superiores ao T0 e ao T1. O T3 foi igual estatisticamente ao T0, T1, T2 e T4. Na Figura 3 D observa-se que houve um aumento linear de $\mathrm{Mn}$ em função do aumento da dose de lodo. Observa-se que somente o tratamento T4 e T5 houve aumento em relação ao teor inicial do solo. Segundo Raij et al. (2001) os teores de Mn apresentaram teores elevados em todos os tratamentos. Na profundidade de 20 a 40 $\mathrm{cm}$ pode se observar na Tabela 8 que o tratamento T2 apresentou um teor de Mn superior que o T0, T1 e T3. O tratamento T3 foi superior ao T1. Com o aumento da dose de lodo aumentou linearmente o $\mathrm{Mn}$ na profundidade de 20 a $40 \mathrm{~cm}$ como mostra a Figura 4 D. Segundo Raij et al. (2001) os tratamentos (T2, T3, T4 e T5) que foram aplicados lodo de esgoto apresentaram teores altos. Para todos os tratamentos na profundidade de 0 a $20 \mathrm{~cm}$ apresentaram superiores em relação a 20 a $40 \mathrm{~cm}$.

Para o $\mathrm{Zn}$ verifica-se na Tabela 7 que ate o tratamento T2 não ocorreu aumento do seu teor. A partir do tratamento T3 foi aumentando o teor de $\mathrm{Zn}$ no solo. A medida que foi aumentando a dose de lodo de esgoto aumentou os teores de Zn no solo em uma forma quadrática como apresenta a Figura 3 E. Todos os tratamentos apresentaram teores altos de Zn, segundo Raij et al. (2001), segundo USEPA (1996) nenhum tratamento apresentou teor tóxico. Comparando os dados iniciais de $\mathrm{Zn}$ todos os tratamentos aumentaram os seus teores. Chiba, Mattiazzo e Oliveira (2008) observaram que com o manejo de aplicações sucessivas de lodo de esgoto na cultura da cana resultou em aumento nos teores de $\mathrm{Zn}$ e $\mathrm{Cu}$ disponíveis nos solo, porem em níveis abaixo dos valores de referencias encontrados na legislação ambiental. Na profundidade de 20 a $40 \mathrm{~cm}$ o tratamento (T5) apresentou um teor de $\mathrm{Zn}$ superior aos outros tratamentos e o T4 foi superior que o T0, T1, T2 e T3 (Tabela 8). Com o aumento da dose de lodo houve um aumento quadrático de $\mathrm{Zn}$ como mostra a Figura 4 D. Segundo Raij et al. (2001) todos os tratamentos apresentaram níveis altos de $\mathrm{Zn}$. Os tratamentos que não foram aplicados lodo (T0 e T1) apresentaram um teor de $\mathrm{Zn}$ maior na profundidade de 20 a $40 \mathrm{~cm}$ em relação a 0 a $20 \mathrm{~cm}$. Os tratamentos que foram aplicados lodo de esgoto (T2, T3, T4 e $\mathrm{T} 5$ ), apresentaram maiores valores na profundidade de 0 a $20 \mathrm{~cm}$. Oliveira et al. (2002) constatou que o Zn se apresenta como um elemento móvel no perfil 
do solo, com grande potencial para atingir as águas subterrâneas por ocasião de aplicações sucessivas de composto de lixo urbano. A movimentação do $\mathrm{Zn}$ em profundidade foi observada em solos tratados com lodo de esgoto (WELCH; LUND, 1984; OLIVEIRA; MATTIAZZO, 2001) e resíduos ácidos de siderurgia (AMARAL SOBRINHO et al., 1998). Segundo Amaral Sobrinho et al. (1998), a mobilidade do Zn está relacionada a sua presença no solo, predominantemente, em formas trocáveis e, portanto, facilmente solúveis.

Em concordância com os dados obtidos neste experimento, Nascimento et al. (2004) observou aumento dos teores de todos os micronutrientes estudados devido a adição de lodo de esgoto ao solo, com destaque à elevação e acúmulo de Zn ao solo na ordem de doze vezes entre a maior dosagem (60 $\left.\mathrm{Mg} \mathrm{ha}^{-1}\right)$ e o tratamento testemunha $\left(0 \mathrm{Mg} \mathrm{ha}^{-1}\right)$, além do Mn na ordem de sete vezes comparando-se a maior e menor doses do experimento.

\section{Conclusões}

Na maior dose de $200 \%$ de $\mathrm{N}$ da necessidade da cultura proveniente de lodo após 7 aplicações de lodo de esgoto promoveu um incremento nos teores de matéria orgânica, P, S, H+Al, CTC, B, Cu, Fe, Mn e $\mathrm{Zn}$ e decréscimo no $\mathrm{pH}$ do solo na profundidade de 0 a $20 \mathrm{~cm}$. Na profundidade de 20 a $40 \mathrm{~cm}$ houve um aumento de K, Ca, SB, B, Cu, Fe, Mn e Zn.

\section{Referencias}

AMARAL SOBRINHO, N. M. B.; VELLOSO, A. C. X.; COSTA, L. M.; OLIVEIRA, C. Mobilidade de metais pesados em solos tratados com resíduos siderúrgico. Revista Brasileira de Ciência do Solo, Viçosa, MG, v. 22 n. 2, p. 345-353, 1998.

BARBOSA, G. M. C.; TAVARES FILHO, J.; FONSECA, I. C. B. Propriedades químicas de um latossolo vermelho eutroférrico após a aplicação por dois anos consecutivos de lodo de esgoto. Acta Scientiarum, Maringá, v. 24, n. 5, p. 1501-1505, 2002.

BOEIRA, R. C.; LIGO, M. A. V.; DYNIA, J. F. Mineralização de nitrogênio em solo tropical tratado com lodo de esgoto. Pesquisa Agropecuária Brasileira, Brasília, v. 37, n. 11, p. 1639-1647, nov. 2002.

BRIGHENTI, A.; CASTRO, C. de; OliveirA, F. A. de. Dessecação em pré semeadura da cultura do girassol (Helianthus annus L.) associada a aplicação de boro. In: SIMPOSIO NACIONAL SOBRE A CULTURA DO GIRASSOL, 4., 2005, Londrina. Resumos... Londrina: EMBRAPA, CNPSo, 2005. p. 12-13.

CAMARGO, F. A. de O.; GIANELLO, C.; TEDESCO, M. J.; VIDOR, C. Nitrogenio organico do solo. In: SANTOS, G. de A.; CAMARGO, F. A. de (Ed.). Fundamentos da matéria orgânica do solo: ecossistemas tropicais e subtropicais. Porto Alegre: Gênesis, 1999. p. 117-137.

CHINO, M.; SHIGEKO, G.; KUMAZAWA, K.; OWA, N.; YOSHIOKA, O.; TAKECHI, N.; INANAGA, S.; INOU, H.; DE-LONG, C.; YOUSSEF, R. A. Behavior of zinc and copper in soil with long term application of sewage sludge. Soil Science and Planta Nutricion, Tokyo, v. 38, n. 1, p. 159-167, 1992.

COELHO, A. J. G.; FOLLE, A. D.; SOUZA, L. M.; BARBOSA, M. A. M.; EIRA, M. T. S. de; BOTEHO, T. S. LANARV, Análise de corretivos, fertilizantes e inoculantes: métodos oficiais. Brasília: Ministério da Agricultura, 1988. $104 \mathrm{p}$.

COMPANIA NACIONAL DO MEIO AMBIENTE CONAMA. Resolução $n^{\circ}$ 375/2006. Disponível em: $<$ http://www.mma.gov.br/post/conama/legiano/>. Acesso em: 10 out. 2006.

DIAS, B. de O. Caracterização da matéria orgânica de latossolo sob aplicação continuada de lodo de esgoto. 2005. Dissertação (Mestrado em Solos e Nutrição de Plantas) - Universidade Federal de Lavras Lavras.

DOWDY, R. H.; LATTERELL, J. K.; HINESLY, T. D.; GROSSMAN, R. B.; SULLIVAN, D. L. Trace metal movement in na aeric Ochaqualf flowing 14 year of annual sludge applications. Journal of Enviromental Quality, Madison, v. 20, n. 1, p. 119-123, 1991.

EMPRESA BRASILEIRA DE PESQUISA AGROPECUARIA - EMBRAPA. Sistema brasileiro de classificação de solos. Rio de Janeiro: EMBRAPA/ CNPSO, 1999. 412 p.

FERNANDES, F.; ANDRAUS, S.; ANDREOLI, C. V.; BONNET, B. R. P.; BORGES, J.C.; CANTO, L. A.; MEDEIROS, M. L. B. Eficiência dos processos de desinfecção do lodo da ETE - Belém com vista a seu uso agrícola. Sanaré, Curitiba, v. 5, n. 5, p. 46-58, 1996.

HORTENSTINE, C. C.; ROTHWELL, D. F. Use of municipal compost in reclamation of phosphatemining sand tailings. Journal of Environmental Quality, Madison, v. 1, n. 4, p. 415-418, 1972. 
KITAMURA, A. E.; ALVES, M. C.; SUZUKI, L. G. A. S.; GONZALEZ, A. P. Recuperação de um solo degradado com a aplicação de adubos verdes e lodo de esgoto. Revista Brasileira de Ciência do Solo, Viçosa, MG, v. 32, n. 1, p. 405-416, 2008.

LAMBAIS, M. R.; de SOUZA, A. G. Impacto de biossólido nas comunidades microbianas dos solos. In: BETTIOL, W.; CAMAGO, O. A. (Ed.). Impacto ambiental do uso agrícola do lodo de esgoto. Jaguariuna: Embrapa Meio Ambiente, 2000. p. 269-279.

MARQUES, M. O. Incorporação de resíduo orgânico em solos cultivado com cana de açúcar. 1996. Tese (Livre Docência) - Faculdade de Ciências Agronômicas e Veterinárias, Universidade Estadual Paulista, Jaboticabal.

MELLO, F. A. F. O. O fósforo no solo e na adubação fosfatada. Piracicaba: Escola Superior de Agricultura Luiz de Queiroz, 1980. 39 p.

MELO, W. J.; MARQUES, M. O.; SANTIAGO, G.; CHELli, R. A.; LEITE, S. A. S. Efeito de doses crescentes de resíduo orgânico sobre frações de matéria orgânica e CTC de um latossolo cultivado com cana-deaçúcar. Revista Brasileira de Ciencia do Solo, Viçosa, MG, v. 18, n. 3, p. 449-455, 1994.

NASCIMENTO, C. W. A.; BARROS, D. A. S.; MELO, E. E. C.; OLIVEIRA, A. B. Alterações químicas em solos e crescimento de milho e feijoeiro após aplicação de lodo de esgoto. Revista Brasileira de Ciência do Solo, Viçosa, MG, v. 28, n. 2, p. 385-392, 2004.

OLIVEIRA, F. C.; MATTIAZO, M. E.; MARCIANO, C. R.; ROSSETTO, R. Efeitos de aplicações sucessivas de lodo de esgoto em um latossolo amarelo distrófico cultivado com cana-de-açucar: carbono orgânico, condutividade elétrica, $\mathrm{pH}$ e CTC. Revista Brasileira de Ciência do Solo, Viçosa, MG, v. 26, n. 2, p. 505-519, abr/ jun. 2002.

OLIVEIRA, F. C.; MATTIAZZO, M. E. Mobilidade de metais pesados em um latossolo Amarelo distrofico tratado com lodo de esgoto e cultivado com cana de açúcar. Scientia Agrícola, Piracicaba, SP, v. 58, n. 4, p. 807-812, 2001.

PEGORINI, E. S.; ANDREOLK, C. V.; SOUZA, M. L.; FERREIRA, A. Qualidade do lodo de esgoto utilizado na reciclagem agrícola na região metropolitana de Curitiba - PR. In: SIMPÓSIO LATINO AMERICANO DE BIOSSÓLIDO, 1., 2003, São Paulo. Anais... São Paulo: [s.n], jun. 2003. 11 p.

PIMENTEL GOMES, F. Curso de estatística experimental. 14. ed. Piracicaba: Ed. do Autor, 2000. 477 p.
RAIJ, B. Van; CANTARELlA, H.; QUAGGIO, J. A.; FURLANI, A. M. C. Recomendações de adubação e calagem para o Estado de São Paulo. 2. ed. Campinas: IAC, 1997. 198 p. (IAC. Boletim técnico, 100).

RAIJ, B. Van; ANDRADE, J.C.; CANTARELA, H.; QUAGGIO, J. A. Análise química para fertilidade de solos tropicais. Campinas: Instituto Agronômico, Fundação IAC, 2001. 285 p.

RIVERO, C.; CHIRENJE, T.; MA, L. Q.; MARTINEZ, $\mathrm{G}$. Influence of composto $\mathrm{n}$ soil organic matter quality under tropical conditions. Geoderma, Amsterdam, v. 1, n. 123, p. $355-361,2004$.

SILVA, F. C.; BOARETO, A. E.; BERTON, R. S.; PEIXE, C. A.; MENDONÇA, E. Cana de açúcar cultivada em solo adubado com biossólido. Pesquisa Agropecuária Brasileira, Brasília, v. 33, n. 1, p. 1-8, 1998.

SILVA, F. C.; BOARETO, A. E.; BERTON, R. S.; ZOTELLI, H. B.; PEXE, C. A.; BERNARDES, E. M. Efeito do lodo de esgoto na fertilidade de um argissolo vermelho amarelo cultivado com cana de açúcar. Pesquisa Agropecuária Brasileira, Brasília, v. 36, n. 5, p. 831-840, maio 2001 .

SILVA, F. C.; BOARETTO, A. E.; BERTON, R. S. Características agrotecnologicas, teores de nutrientes e de metais pesados em cana-de-açucar (soqueira), cultivada em solos adubado com o lodo de esgoto. In: CONGRESSO BRASILEIRO DE CIENCIA DO SOLO, 25., 1995, Viçosa. Anais... Viçosa: SBCS/UFV, 1995. p. 2279-2287.

SOARES, E. M. B.; SUKVA, C. A.; DIAS, B. de O.; BETTIOL, W.; BELIZARIO, M. H. Frações da matéria orgânica de latossolo sob influencia de dose de lodo de esgoto. Pesquisa Agropecuária Brasileira, Brasília, v. 43, n. 9, p. 1231-1240, 2008.

TRANNIN, I. C. de B. Avaliação agronômica de um biossolido industrial e de seus efeitos sobre atributos do solo. 2004. Tese (Doutorado em Solos e Nutrição de Plantas) - Universidade Federal de Lavras, Lavras, MG.

TRANNIN, I. C. de B.; SILVEIRA, J. O.; MOREIRA, F. $\mathrm{M}$. de $\mathrm{S}$. Atributos químicos e físicos de um solo tratado com biossolido industrial e cultivado com milho. Revista Brasileira de Engenharia Agrícola e Ambiental, v. 12, n. 3, p. 223-230, 2008.

UNIVERSITY STATES EPA- USEPA. Standards for the use and disposal of sewage sludge. Washington, Dc, 1996. (Code of federal regulations $40 \mathrm{CFR}$, part 503).

VAZ, L. M. S.; GONÇALVES, J. L. M. Uso de biossolidos em povoamento de Eucaliptus grndis: efeito em atributos químicos do solo, no crescimento e na 
absorção de nutrientes. Revista Brasileira de Ciência do Solo, Viçosa, MG, v. 26, n. 3, p. 747-758, jul./set. 2002.

WELCH, J. E.; LUND, L. J. Zinc movement in sewage sludge-trested soil as influenced by soil properties, irrigation water quality, and soil moisture level. Soil Science, New Brunswick, v. 147, n. 3, p. 208-214, 1989.
WILLIAMS, D. E.; VLAMIS, J.; PUKITE, A. H.; COREY, J. E. Metal movement in sludge-amended soils: a nine year study. Soil Science, New Brunswick, v. 143, n. 2, p. 124-131, 1987. 
